University of Wollongong

Research Online

Faculty of Engineering and Information

Faculty of Engineering and Information

Sciences - Papers: Part B

Sciences

2019

Aerodynamic analysis of a stator-augmented linear cascade wind turbine

Seyed A. Jafari

Western Sydney University, sahj551@uowmail.edu.au

Kenny Kwok

University of Sydney

Farzad Safaei

University of Wollongong, farzad@uow.edu.au

Buyung Kosasih

University of Wollongong, buyung@uow.edu.au

Ming Zhao

Western Sydney University

Follow this and additional works at: https://ro.uow.edu.au/eispapers1

Part of the Engineering Commons, and the Science and Technology Studies Commons

Research Online is the open access institutional repository for the University of Wollongong. For further information contact the UOW Library: research-pubs@uow.edu.au 


\title{
Aerodynamic analysis of a stator-augmented linear cascade wind turbine
}

\begin{abstract}
This study proposes to attach stator vanes to PowerWindow, a linear cascade wind turbine, to improve the flow direction in the device. By controlling the angle of attack, the stator vanes increase the acting force and decrease the undesirable force on PowerWindow blades. An analytical model using blade element momentum theory is developed for the new configuration, referred to as stator-augmented PowerWindow. The analytical model has been verified by a computational fluid dynamic simulation. This study shows that the stator vanes are able to minimize/neutralize the undesirable axial force on PowerWindow so that the thrust coefficient decreases from 0.035 in the original model to -0.005 in the stator-augmented one. In addition, by increasing the acting force on the blades, the stator augmentation will simultaneously enhance the coefficient of performance by up to $10 \%$. This study also shows that by using stator vanes to control the angle of attack, unlike in the original PowerWindow, the direction of rotation of the stator-augmented PowerWindow will remain the same regardless of the wind direction, increasing the utility of the device in practice.
\end{abstract}

\section{Disciplines}

Engineering | Science and Technology Studies

\section{Publication Details}

S. Jafari, K. C.S. Kwok, F. Safaei, B. Kosasih \& M. Zhao, "Aerodynamic analysis of a stator-augmented linear cascade wind turbine," Wind Energy, vol. 22, (8) pp. 1148-1163, 2019. 


\title{
Aerodynamic Analysis of a Stator-augmented Linear Cascade Wind Turbine
}

\author{
S. A H. Jafari ${ }^{\text {a* }}$, K.C.S. Kwok ${ }^{\text {b }}$, F. Safaei ${ }^{\text {c }}$, B. Kosasih ${ }^{\text {d }}$, M. Zhao ${ }^{\text {e }}$ \\ ${ }^{a}$ Center for Infrastructure Engineering, Western Sydney University, Kingswood, NSW 2747, \\ Australia \\ ${ }^{\mathrm{b}}$ School of Civil Engineering, The University of Sydney, Camperdown, NSW 2006, Australia \\ ${ }^{\mathrm{c}}$ School of Electrical, Computer and Telecommunications Engineering, University of \\ Wollongong, Wollongong, NSW 2500, Australia \\ ${ }^{\mathrm{d}}$ School of Mechanical, Materials and Mechatronic Engineering, University of Wollongong, \\ Wollongong, NSW 2500, Australia \\ ${ }^{e}$ School of Engineering, Western Sydney University, Kingswood, NSW 2747, Australia \\ *e-mail: S.jafari@westernsydney.edu.au (Corresponding Author)
}

\begin{abstract}
This study proposes to attach stator vanes to PowerWindow, a linear cascade wind turbine, to improve the flow direction in the device. By controlling the angle of attack, the stator vanes increase the acting force and decrease the undesirable force on PowerWindow blades. An Analytical model using blade element momentum theory is developed for the new configuration, referred to as stator-augmented PowerWindow. The analytical model has been verified by a computational fluid dynamic simulation. This study shows that the stator vanes are able to minimize/neutralize the undesirable axial force on PowerWindow so that the thrust coefficient decreases from 0.035 in the original model to -0.005 in the stator-augmented one. In addition, by increasing the acting force on the blades, the stator-augmentation will simultaneously enhance the coefficient of performance by up to $10 \%$. This study also shows that by using stator vanes to control the angle of attack, unlike in the original PowerWindow, the direction of rotation of the stator-augmented PowerWindow will remain the same regardless of the wind direction, increasing the utility of the device in practice.
\end{abstract}

Keywords: blade element momentum theory, computational fluid dynamics, linear cascade, wind turbine, angle of attack, coefficient of performance, stator vanes, PowerWindow 


\section{Nomenclature}

A

$a_{f}$

$B$

$C_{D}$

$C_{L}$

$C_{P}$

$C_{s p}$

$F_{D}$

$F_{L}$

$\dot{\mathrm{m}}$

$N$

$P$

$p$

$R_{V}$

V

$V_{\text {rel }}$

$\alpha$

$\beta$

$\theta_{b}$

$\theta_{v}$
PowerWindow frontal area $\left(\mathrm{m}^{2}\right)$

Axial induction factor (dimensionless)

Airfoil plan area $\left(\mathrm{m}^{2}\right)$

Drag coefficient (dimensionless), Eq. 3

Lift coefficient (dimensionless), Eq. 4

Coefficient of performance (dimensionless), Eq. 1

Surface pressure coefficient (dimensionless), Eq. 31

Drag force (N)

Lift force $(\mathrm{N})$

Mass flow rate $\left(\mathrm{kg} \mathrm{s}^{-1}\right)$

Number of blades at the front/rear side of PowerWindow

Power (Watt)

Pressure $(\mathrm{Pa})$

Velocity ratio (dimensionless), Eq. 32

Air velocity in horizontal direction $\left(\mathrm{m} \mathrm{s}^{-1}\right)$

Wind relative velocity to the blades $\left(\mathrm{m} \mathrm{s}^{-1}\right)$

Angle of attack $\left(^{\circ}\right)$

Effective angle $\left(^{\circ}\right)$

Blade pitch angle $\left({ }^{\circ}\right)$

Vane pitch angle $\left(^{\circ}\right)$ 
$\mathcal{E}$

$\sigma$

$\rho$

$\lambda$
Affected flow ratio (dimensionless)

Solidity (dimensionless), Eq. 5

Air density $\left(\mathrm{kg} \mathrm{m}^{-3}\right)$

Blade speed ratio (dimensionless) 


\section{Introduction}

Linear Cascade Wind Turbines (LCWTs) are a new generation of wind turbines. Unlike the conventional horizontal axis wind turbine (HAWT) and vertical axis wind turbines (VAWT), the blades of LCWTs do not rotate around the rotor axis but move translationally in a direction perpendicular to the approach wind direction. PowerWindow, shown in Figure 1(a), is a compact modular LCWT which can easily fit into any designated area in a building. It is also capable of generating electricity even when the ratio of blade speed to wind speed (referred to as the blade speed ratio, $\lambda$ ) is quite low. Therefore, it can be a safe option for application in built environments.

Power generation mechanism of PowerWindow is similar to Variable-Geometry OvalTrajectory (VGOT) Darrieus turbine ${ }^{1-3}$, which is a modified version of a straight-blade Darrieus or H-rotor Vertical Axis Wind Turbine (VAWT) ${ }^{4}$. Similar to VGOT, PowerWindow has an adjustable blade pitch angle $\left(\theta_{b}\right)$, which enables optimizing the angle of attack $(\alpha)$ when exposed to different approach wind velocities. Here, $\theta_{b}$ refers to the angle between the chord length of the blades and the horizontal direction. Therefore, $\alpha$ equals $\theta_{b}$ if the blades are stationary and is smaller than $\theta_{b}$ as the blades move. Note that the pitch angle in HAWTs and VAWTs may very along the span of the blade, while in PowerWindow $\theta_{b}$ is constant spanwise. When $\theta_{b} \neq 0$, it is required that the angle flips to $-\theta_{b}$ when the blades roll over. A passive mechanism for this purpose has been designed for PowerWindow as described in Section 2.

The power generation performance of a wind turbine is dependent on different design parameters such as airfoil shape, solidity, pitch angle and rotating speed. Mohamed ${ }^{5}$ investigated performance of a H-rotor Darrieus wind turbine using 20 different airfoil shapes and increased the power output coefficient by $27 \%$. Mohamed ${ }^{6}$ also investigated the impacts of solidity on the performance of a small H-rotor Darrieus turbines and found that the rotational speed of the rotor deacreases by increasing the solidity. Lee et al. ${ }^{7}$ investigated effects of the pitch angle and rotating speed on aerodynamic performance of a counter-rotating wind turbine and showed that the rotational speeds of the wind turbine rotors are strongly dependent on their pitch angles, while both the parameters (pitch angle and rotating speed) significantly affect the aerodynamic performance of the turbine. 


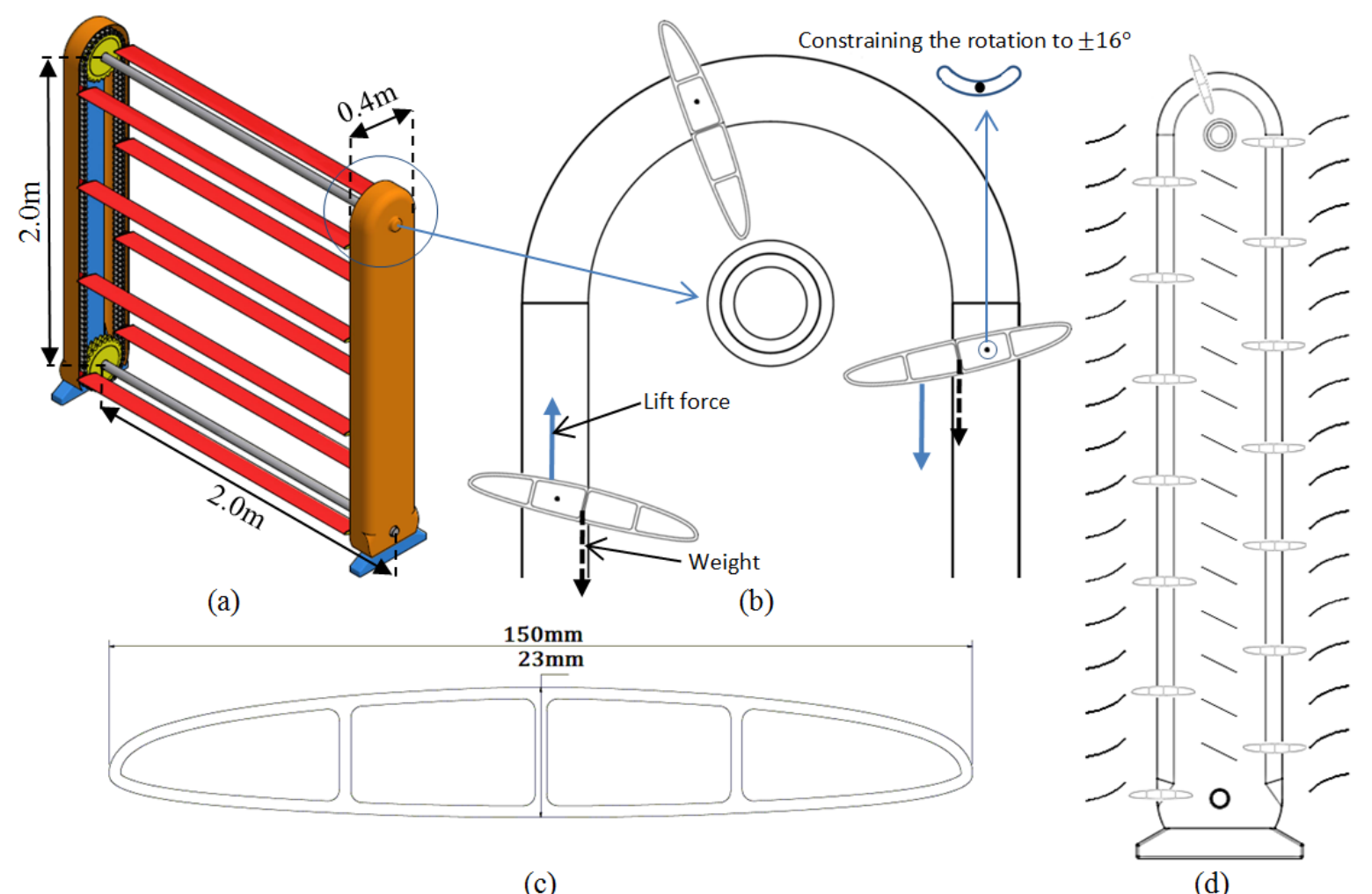

Figure 1 (a) Sketch of the PowerWindow prototype, (b) Blades changing their side and orientation at the top of PowerWindow, (c) Cross section view of the airfoil blades, and (d) Sketch of the stator-augmented

PowerWindow (from side view).

In our previous work ${ }^{8}$, we examined the effect of solidity on the performance of PowerWindow. The aim of this paper is to explore the optimization of the angle of attack. It can be observed that the optimum $\alpha$ is dependent on the wind speed. Therefore, one approach would be to adjust the pitch angle $\theta_{b}$ for different approach wind velocities. It is conceivable to design an active pitch angle control mechanism for this purpose. However, this addition has a number of drawbacks. Firstly, it increases the complexity (and cost) of the mechanism of attachment between the blades and the belt/chain. Secondly, controlling the drag force is not easy and may result in undesirable load on the system. In the wind tunnel test on the prototype model ${ }^{9}, \theta_{b}$ could be altered manually. The results presented in [5] are for $\theta_{b}=16^{\circ}$. But increasing $\theta_{b}$ would also increase the axial load (aerodynamic force along the wind direction) on PowerWindow ${ }^{10}$.

This study aims to develop an alternative approach to optimize $\alpha$ and enhance power generation performance of PowerWindow. Instead of optimizing $\theta_{b}$ for the turbine blades, stator vanes are attached to the device, and the vane pitch angle $\left(\theta_{v}\right)$ is used to control the flow direction toward the blades in order to create a desirable $\alpha$. This approach has been widely used in gas turbines. As shown in Figure 2, in gas turbines, stationary vanes, also known as stator are located 
between the rotors and redirect the flow. When fluid passes through a stator, the velocity of fluid increases due to its special shape and a part of enthalpy gets converted into kinetic energy ${ }^{11,12}$. The angle of the stator vanes can be adjusted to redirect the flow and create the optimum $\alpha$ over the rotor blades based on the flow velocity. The black vectors show the absolute velocity of the flow and blue ones show the relative velocity of the flow to the rotor blades.

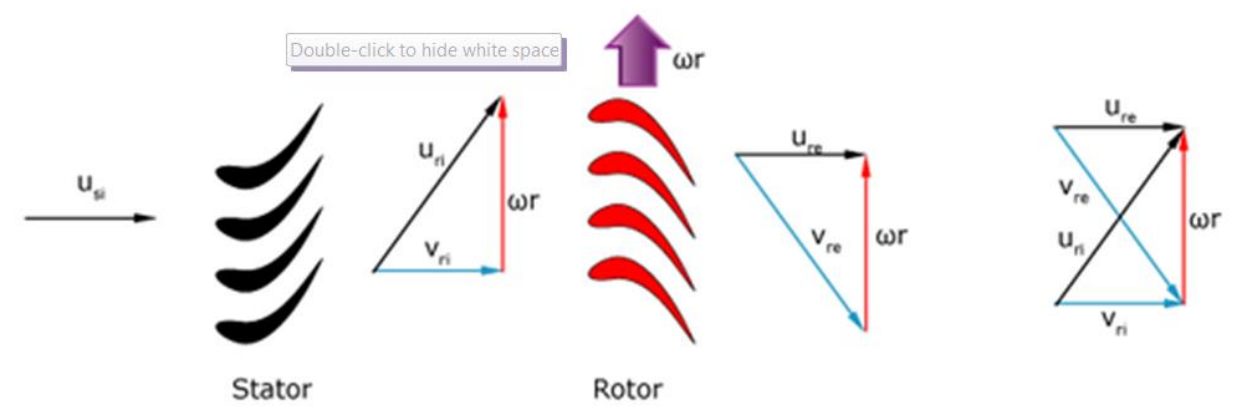

Figure 2 Absolute (black vectors) and relative (blue vectors) velocity of the flow to the rotor blades.

This study proposes to use stator vanes to improve the flow direction in PowerWindow. This new configuration (with stator vanes attached to the original PowerWindow) is referred to as stator-augmented PowerWindow. It is demonstrated that by attaching stator vanes and adjusting their angle, it is possible to increase the acting force (vertical load) while at the same time having the ability to decrease/control the undesirable force (axial load) on PowerWindow. The complexity of the device is also significantly reduced, because neither the active mechanism for adjusting the blades' pitch angle in response variations of wind speed nor the passive mechanism for flipping the pitch angle in each rotation are needed. This is because the pitch angle will be set at a fixed value of $\theta_{b}=0$. Another advantage of using stator vanes to control the angle of attack is that the direction of rotation of PowerWindow will remain the same regardless of the wind direction. In the original PowerWindow, when the wind direction is reversed, the turbine will also rotate in the opposite direction. The stator-augmented design, therefore, will be particularly useful for fixed inbuilding installations.

The effect of stator augmentation has been investigated on the coefficient of performance $\left(C_{P}\right)$ and the thrust coefficient $\left(C_{T}\right)$ of the stator-augmented PowerWindow. $C_{P}$ refers to the ratio of the power captured by the generator to the entire wind energy passing through its swept area and $C_{T}$ shows the ratio of the force exerted on a turbine rotor to the dynamic pressure of the approach flow: 


$$
\begin{aligned}
C_{P} & =\frac{P_{\text {captured }}}{1 / 2\left(\rho A V^{3}\right)} \\
C_{T} & =\frac{F_{\chi}}{1 / 2\left(\rho A V^{2}\right)}
\end{aligned}
$$

when $\rho$ is the density of the flow, $A$ is swept area.

In this study, Blade Element Momentum (BEM) theory has been selected for analysing the power generation of the stator-augmented PowerWindow, as this approach has shown to be very effective for design and optimization of HAWTs ${ }^{13-15}$ and VAWTs ${ }^{16}$. In addition, we have developed a similar model for the original PowerWindow (without the stator vanes) in our previous research ${ }^{10}$, hence, comparative studies can be conducted on $C_{P}$ and $C_{T}$ of both configurations. A Computational Fluid Dynamic (CFD) model of the stator-augmented PowerWIndow has also been developed to verify the analytical results by simulation.

\section{Description of the Original and Stator-augmented PowerWindow}

A sketch of the original PowerWindow is shown in Figure 1 (a). In PowerWindow, the approach wind exerts lift force on the blades pushing the front blades upward and the rear ones downward causing the belt to roll. As the belt goes around, the blades change side and orientation. The blades are attached to the belt in a way that they can rotate about the support point with $\pm \theta_{b}$ as shown in Figure 1 (b). The blade's angular rotation is constrained by a simple pin-and-groove mechanism, which limits $\theta_{b}$ to some upper bound value for the pitch angle.

PowerWindow blades have a symmetrical shape as shown in Figure 1 (c). In the original PowerWindow, the point of attachment is at about a third of the chord length, which is forward of the centre of mass but behind the centre of pressure in the upwind state. When a blade is at the front (upwind plane), the force of gravity acting on the centre of mass and the lift force acting at the centre of pressure make the blade rotate in the clockwise direction. When a blade is at the rear (downwind plane), both the gravity and the pressure force makes the blade rotate in the anticlockwise direction.

In PowerWindow, the lift forces acting on the front and the rear blades oppose each other. Therefore, the original PowerWindow is designed such that blades 'flip over' to $-\theta_{b}$ in each rotation. While as shown in Figure 1 (d), in the stator-augmented PowerWindow, $\theta_{b}=0$ and using the stator vanes $\theta_{v}$ adjusts $\alpha$ over the front and rear blades. The point of attachment should also be 
at the middle of the blades. The stator vanes' pitch angle $\theta_{v}$ creates an upward lift on the front and a downward lift on the rear blades, whether the approach wind comes from front or back. This mechanism allows the stator-augmented PowerWindow to operate effectively in clockwise direction with respect to bidirectional approach wind. $\theta_{v}$ for the front and rear vanes needs to be identical but it can be different for the middle vanes. As a simple preliminary configuration for the analysis and evaluation of this paper, the stator vanes have been selected to have the same length and distance from each other as the chord length of the blades, and $\theta_{v}$ is selected for every vane. The middle vanes are simple flat vanes but the front and rear vanes are designed with a curved shape to minimize flow separation from their surface. Further details are discussed later in computational fluid dynamic model.

\section{Blade Element Momentum Model}

The basic aerodynamic analysis of the BEM theory is based on Glauert's airscrew theory ${ }^{17}$, which was initially developed for the analysis of propellers, particularly within the helicopter industry ${ }^{18}$. This theory has recently been used in the analysis of HAWT ${ }^{15,19-21}$, and VAWT ${ }^{16}$ using tabulated airfoil lift and drag coefficients $\left(C_{L}\right.$ and $\left.C_{D}\right)$. For most of the well-known airfoils, the recorded databases of $C_{L}$ and $C_{D}$ is available for a limited range of angle of attack $(\alpha)$, Reynolds and Mach numbers. However, it has been reported that the $C_{L}$ and $C_{D}$ values are usually higher than those which are typically experienced by wind turbine blades during the operation ${ }^{16}$.

\subsection{Aerodynamic of the PowerWindow blade and cascade configuration}

In this study, $k-\omega$ shear stress transport (SST) turbulence model was used in the CFD simulations to calculate the lift and drag coefficient $\left(C_{L}\right.$ and $\left.C_{D}\right)$ values of airfoil blades. The BEM theory was modified by replacing $C_{L}$ and $C_{D}$ of the isolated blade by the $C_{L}$ and $C_{D}$ of the cascade configuration, which takes into account the viscous loss and effects of other characteristic changes due to the cascade configuration of the PowerWindow. $C_{L}$ and $C_{D}$ are presented below:

$$
\begin{aligned}
& C_{L}=\frac{\text { Lift }}{\frac{1}{2} \rho B V^{2}} \\
& C_{D}=\frac{\text { Drag }}{\frac{1}{2} \rho B V^{2}}
\end{aligned}
$$

Where, $\rho$ is air density, $B$ is airfoil plan area and $V$ is the air velocity. 
In PowerWindow, solidity $(\sigma)$ is the ratio of the total surface area of the windward side of the (front/rear) blades to the total area of PowerWindow exposed to the approach wind:

$$
\sigma=N B / A
$$

where $N, B$ and $A$ represent the number of the blades, area of each blade and area of PowerWindow respectively.

$C_{L}$ and $C_{D}$ of the linear cascade (a series of airfoils located in a line parallel to each other) configuration are calculated for the original PowerWindow, where $\sigma=0.428$, and also for some higher $\sigma$ values: $\sigma=0.857$ and 1.714 , to demonstrate the influence of $\sigma$ on the aerodynamic performance of PowerWindow. In all simulations, the inlet wind velocity was set to $8 \mathrm{~ms}^{-1}$, which is achievable in appropriate places in urban environments. The Reynolds and the Mach number based on chord length the airfoil and room temperature $(300 \mathrm{~K})$ are $7.1 \times 10^{4}$ and $2.33 \times 10^{-2}$, respectively. Figures 3(a) and (b) show the numerical results of $C_{L}$ and $C_{D}$ for an isolated airfoil and one of the airfoil in linear cascade configuration with $\sigma=0.428,0.857$ and 1.714 against a range of $\alpha:-14^{\circ}<\alpha<36^{\circ}$. Polynomial curves have been fitted to the $C_{L}$ and $C_{D}$ values at $\sigma=$ 0.428 to present their relation with $\alpha$. 


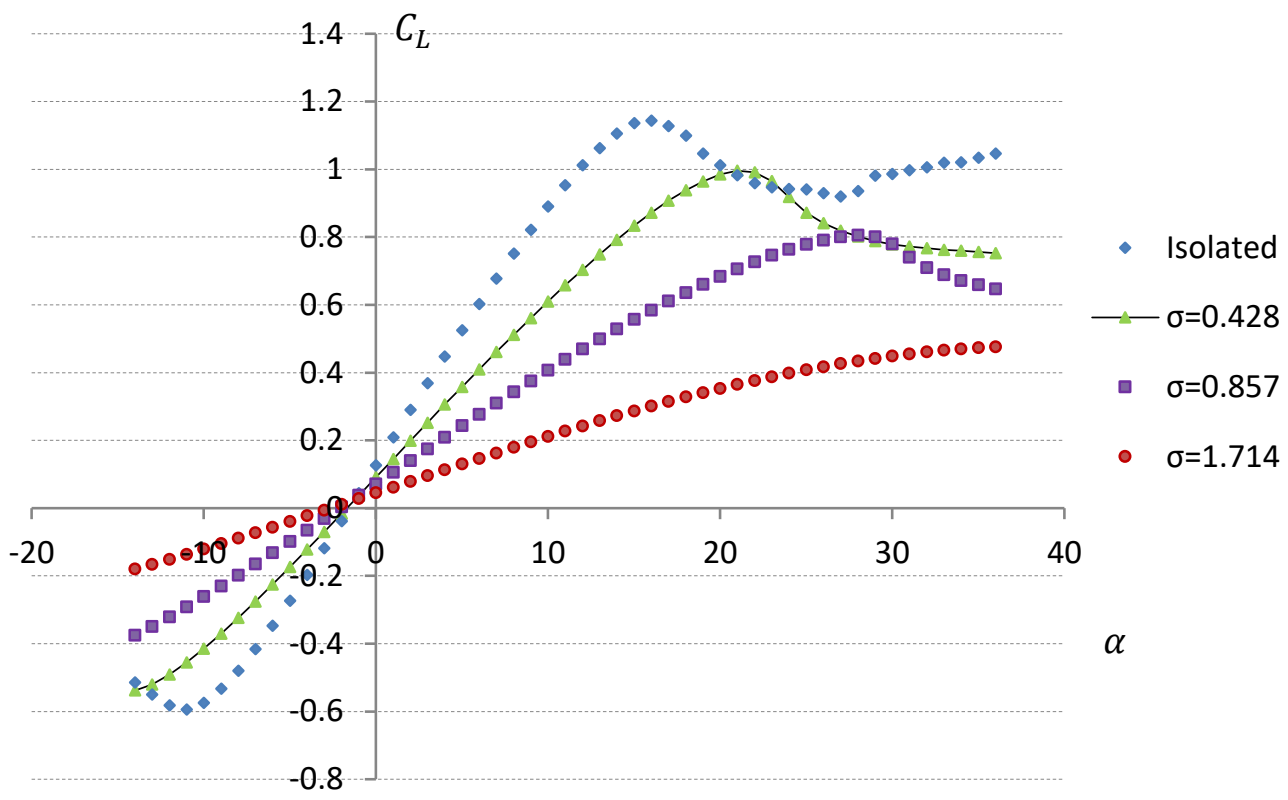

(a)

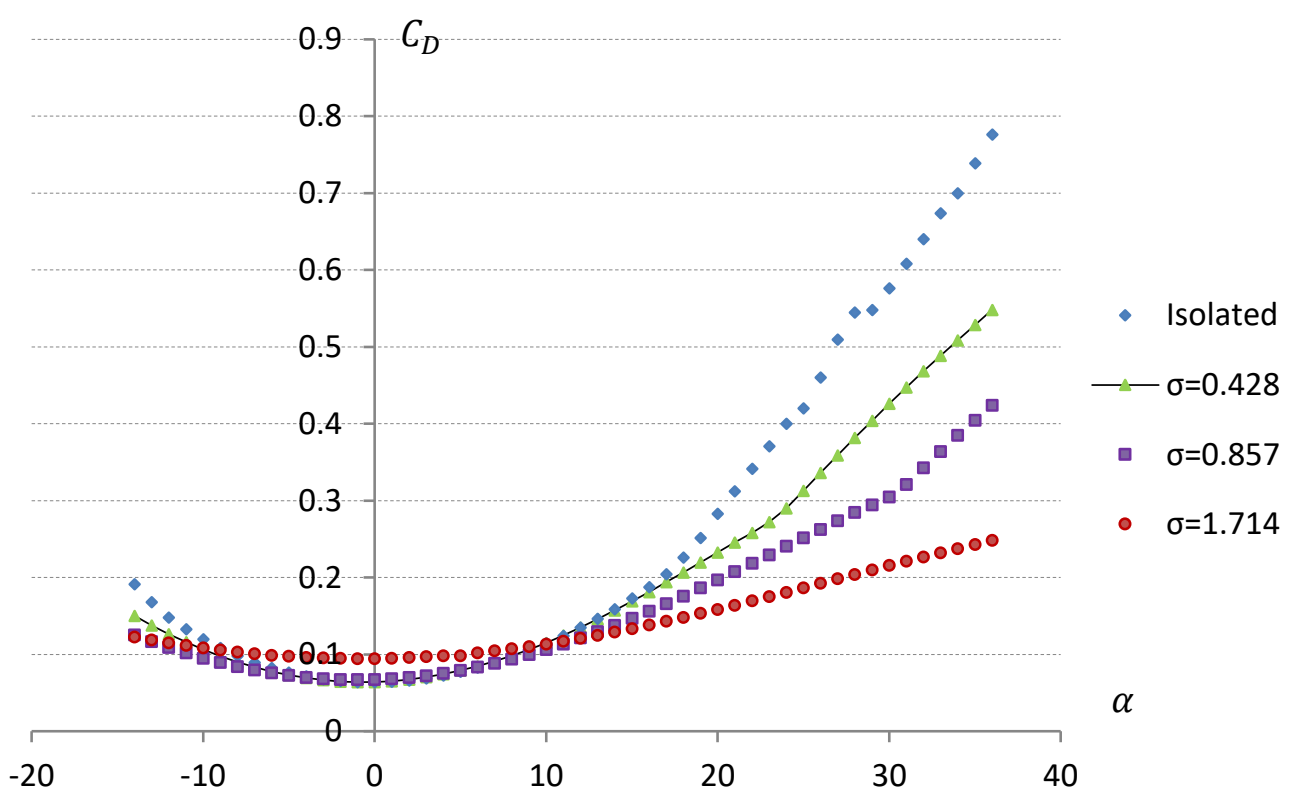

(b)

Figure 3 (a) $C_{L}$ and (b) $C_{D}$ extracted for the isolated airfoil and the linear cascade configuration with $\sigma=0.428,0.857$ and 1.714 against a range of $\alpha$ : $-14^{\circ}<\alpha<36^{\circ} . \quad C_{L}=3.93 \times$ $10^{-15} \alpha^{11}-4.35 \times 10^{-13} 3 \alpha^{10}+1.47 \times 10^{-11} \alpha^{9}-2.55 \times 10^{-11} \alpha^{8}-6.89 \times 10^{-9} \alpha^{7}+$ $7.05 \times 10^{-8} \alpha^{6}+9.76 \times 10^{-7} \alpha^{5}-1.14 \times 10^{-5} \alpha^{4}-8.05 \times 10^{-5} \alpha^{3}+5.68 \times 10^{-4} \alpha^{2}+$ $5.48 \times 10^{-2} \alpha+8.73 \times 10^{-2}$ and $C_{D}=-3.02 \times 10^{-9} \alpha^{5}+1.86 \times 10^{-7} \alpha^{4}-4.39 \times 10^{-6} \alpha^{3}+$ $4.07 \times 10^{-4} \alpha^{2}+9.43 \times 10^{-4} \alpha+6.63 \times 10^{-2}$. 


\subsection{Momentum Analysis of Stator-augmented PowerWindow}

Analytical model of the original PowerWindow has been developed using BEM theory in a previous study ${ }^{10}$. This study develops a BEM model to analyze power generation mechanism of a stator-augmented PowerWindow and compare that with the original PowerWindow. Figure 4 (a) and (b) show a flow stream tube around the original and stator-augmented PowerWindow. In the stator-augmented PowerWindow, vanes are attached to the front, middle and rear of the blades. Blades are attached horizontally to the chains and the stator vanes create a desirable $\alpha$ on them.

The flow stream in and around PowerWindow is divided into 5 main zones and flow characteristics of the approach wind is assumed to be changing while proceeding from one zone to the next one. The upstream flow far from PowerWindow is before Boundary 0. Boundaries 1 and 2 are the leading edge and the trailing edge of the front blades of PowerWindow. Boundaries 3 and 4 are the leading edge and trailing edge of the rear blades of PowerWindow. In Figure 4(b), boundaries $1_{s}$ and $4_{s}$ are added to indicate the flow at upstream of the front stator vanes and downstream of the rear stator vanes respectively. Beyond Boundary 5 is the downstream flow far from PowerWindow. The velocity and pressure at each boundary $i=1$ or 2 is denoted by $V_{i}$ and $P_{i}$ respectively.

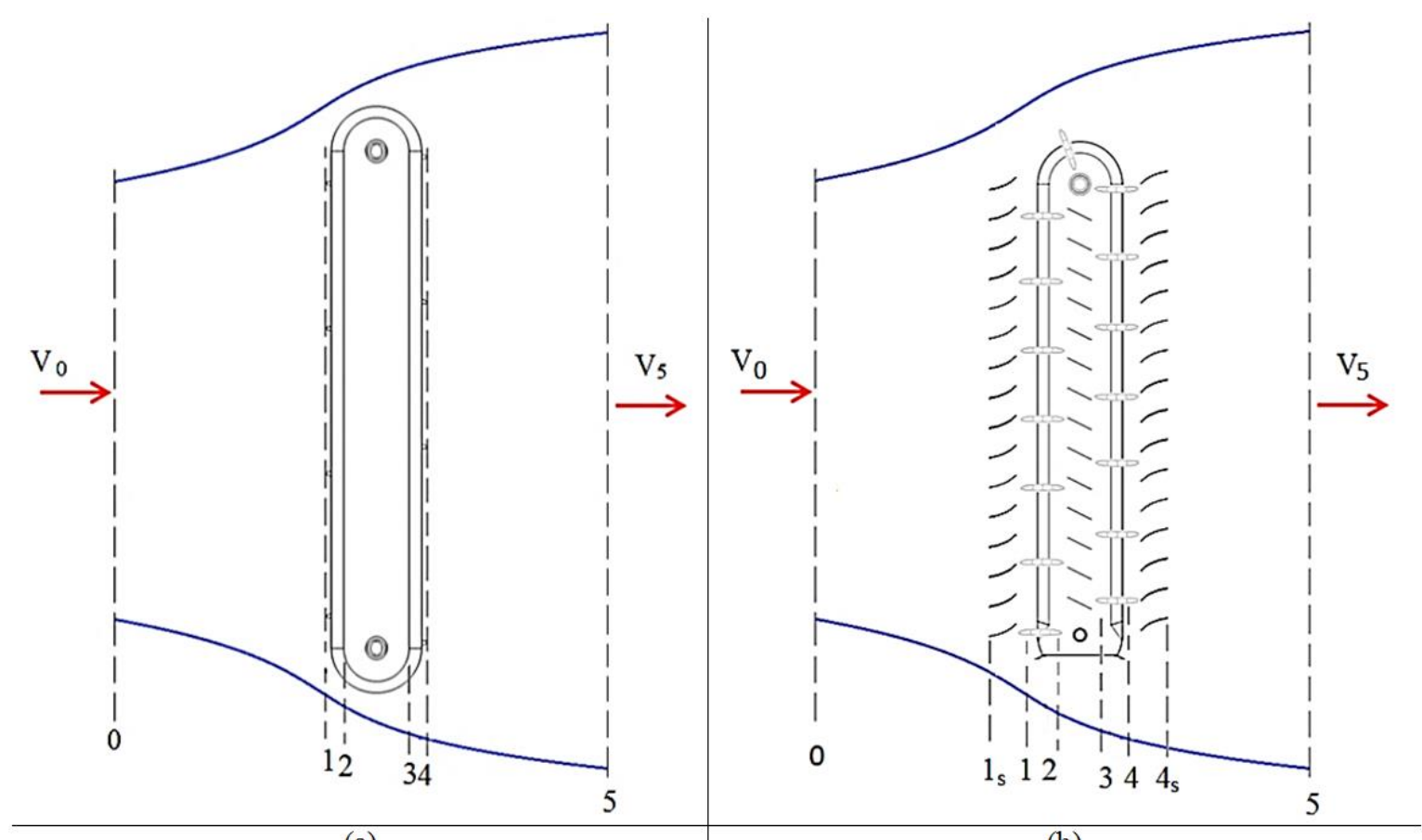

(a)

(b)

Figure 4 Flow stream passing through the (a) original and (b) stator-augmented PowerWindow from far upstream to far downstream. 
Prior to entering PowerWindow between 0 and 1, flow expands and its velocity reduces from $V_{0, x}$ to $V_{1, x}$ and air pressure increases from $p_{0}$ to $p_{1}$ (note that $p_{0}=p_{a t m}$ ). By passing across the front and rear blades (and vanes) pressure of the flow drops from $p_{1}$ to $p_{2}\left(p_{2}<p_{1}\right)$ and $p_{3}$ to $p_{4}\left(p_{4}<p_{3}\right)$. Within the space between the front and rear blades, the flow does not expand, so it is reasonable to assume that $V_{2, x}=V_{3, x}$. Therefore, due to the close vicinity of the stator vanes and PowerWindow blades it can be assumed that: $V_{1, x} \equiv V_{1 s, x} \equiv V_{2, x} \equiv V_{3, x} \equiv V_{4, x} \equiv V_{4 s, x}$. However, in the original PowerWindow: $p_{2}=p_{3}$, while in the stator-augmented PowerWindow pressure drops when passing across the middle vanes and: $p_{3}<p_{2}$. Therefore, in the stator-augmented PowerWindow: $p_{4 s}<p_{4}<p_{3}<p_{2}<p_{1}<p_{1 s}$. Finally, in the second expansion air velocity reduces from $V_{4, x}$ to $V_{5, x}$ and its pressure increases from $p_{4}$ to $p_{5}\left(p_{5}=p_{a t m}\right)$.

An axial induction factor $\left(a_{f}\right)$ is defined as the ratio of decrease in velocity to the approach velocity:

$$
a_{f}=\frac{V_{0}-V_{1}}{V_{0}}=\frac{V_{4}-V_{5}}{V_{0}}
$$

It should be noted that a unified $a_{f}$ is considered for the entire blade system since the gap between the front and rear blades is not large enough for wind to recover its velocity/pressure. When $p_{3}=p_{2}$ and $V_{1, x}=V_{2, x}=V_{3, x}=V_{4, x}$, the power extracted by the front and rear blades can be calculated by the following equations:

$$
\begin{aligned}
& P_{\text {front }}=V_{1, x} A\left(p_{1}-p_{2}\right)=V_{0, x} A\left(1-a_{f}\right)\left(p_{1}-p_{2}\right) \\
& P_{\text {rear }}=V_{1, x} A\left(p_{3}-p_{4}\right)=V_{0, x} A\left(1-a_{f}\right)\left(p_{3}-p_{4}\right)
\end{aligned}
$$

The pressure drop created by the stator vanes depends on length of the vanes, their distance from each other, and velocity of the approach wind. However, assuming inviscid flow and ignoring the pressure drop, the total wind power captured by the device can be calculated using the following equation:

$$
P_{\text {total }}=V_{\text {average }} A\left(p_{1}-p_{4}\right)
$$

where $A$ is to the frontal area of PowerWindow.

As $a_{f}$ assumes equal air velocity reduction at upstream and downstream of PowerWindow, $V_{5}$ can be calculated based on $V_{1}$ as follows: 
$V_{5, x}=V_{0, x}\left(1-2 a_{f}\right)$

$V_{\text {average }}$ can be calculated as below:

$V_{\text {average }}=\frac{V_{0, x}+V_{5, x}}{2}=\frac{V_{0, x}+V_{0, x}\left(1-2 a_{f}\right)}{2}=V_{0, x}\left(1-a_{f}\right)$

$P_{1}-P_{4}$ can be presented based on the velocities:

$$
\begin{aligned}
P_{1}-P_{4}=\frac{1}{2} \rho V_{0, x}{ }^{2}-\frac{1}{2} \rho V_{5, x}{ }^{2} & =\frac{1}{2} \rho V_{0, x}{ }^{2}\left(1-\left(1-2 a_{f}\right)^{2}\right)=\frac{1}{2} \rho V_{0, x}{ }^{2}\left(1-\left(1-4 a_{f}+\right.\right. \\
\left.\left.4 a_{f}^{2}\right)\right)=\frac{1}{2} \rho V_{0, x}{ }^{2}\left(4 a_{f}-4{a_{f}}^{2}\right) & =\frac{1}{2} \rho V_{0, x}{ }^{2} 4 a_{f}\left(1-a_{f}\right)
\end{aligned}
$$

Combining Equations 9, 11 and 12 and considering $P_{0}=P_{5}=P_{a t m}$ and $V_{0, x}=V_{\text {wind }}, P_{\text {total }}$ can be calculated as follows:

$$
P_{P W, \text { total }}=\frac{1}{2} \rho A V_{\text {wind }}^{3} 4 a_{f}\left(1-a_{f}\right)^{2}
$$

The effect of the tangential (vertical) momentum and the induction factor $\left(a_{f}^{\prime}\right)$ is assumed to be negligible on power generation of PowerWindow because the front and rear blades are chained together and the inlet flow simultaneously moves the front blades up and the rear ones down with the same velocity.

\subsection{Blade Element Analysis of Stator-augmented PowerWindow}

Blade element theory divides a blade into small elements so that the forces on each of these small elements can be individually calculated. These forces are then integrated along the entire blade and over one rotor revolution in order to obtain the forces produced by the entire propeller or rotor $^{22}$. Figure 5 (a) and (b) show the aerodynamic forces on the blades of the original and statoraugmented PowerWindow respectively. The horizontal $\left(F_{x}\right)$ and vertical $\left(F_{y}\right)$ forces can be calculated along entire the span of the front and rear blades by the following equations:

$$
\begin{aligned}
& F_{x}=F_{L_{x}}-F_{D_{x}}=\left(F_{L} \sin \alpha-F_{D} \cos \alpha\right) \\
& F_{y}=F_{L_{y}}+F_{D_{y}}=\left(F_{L} \cos \alpha+F_{D} \sin \alpha\right)
\end{aligned}
$$



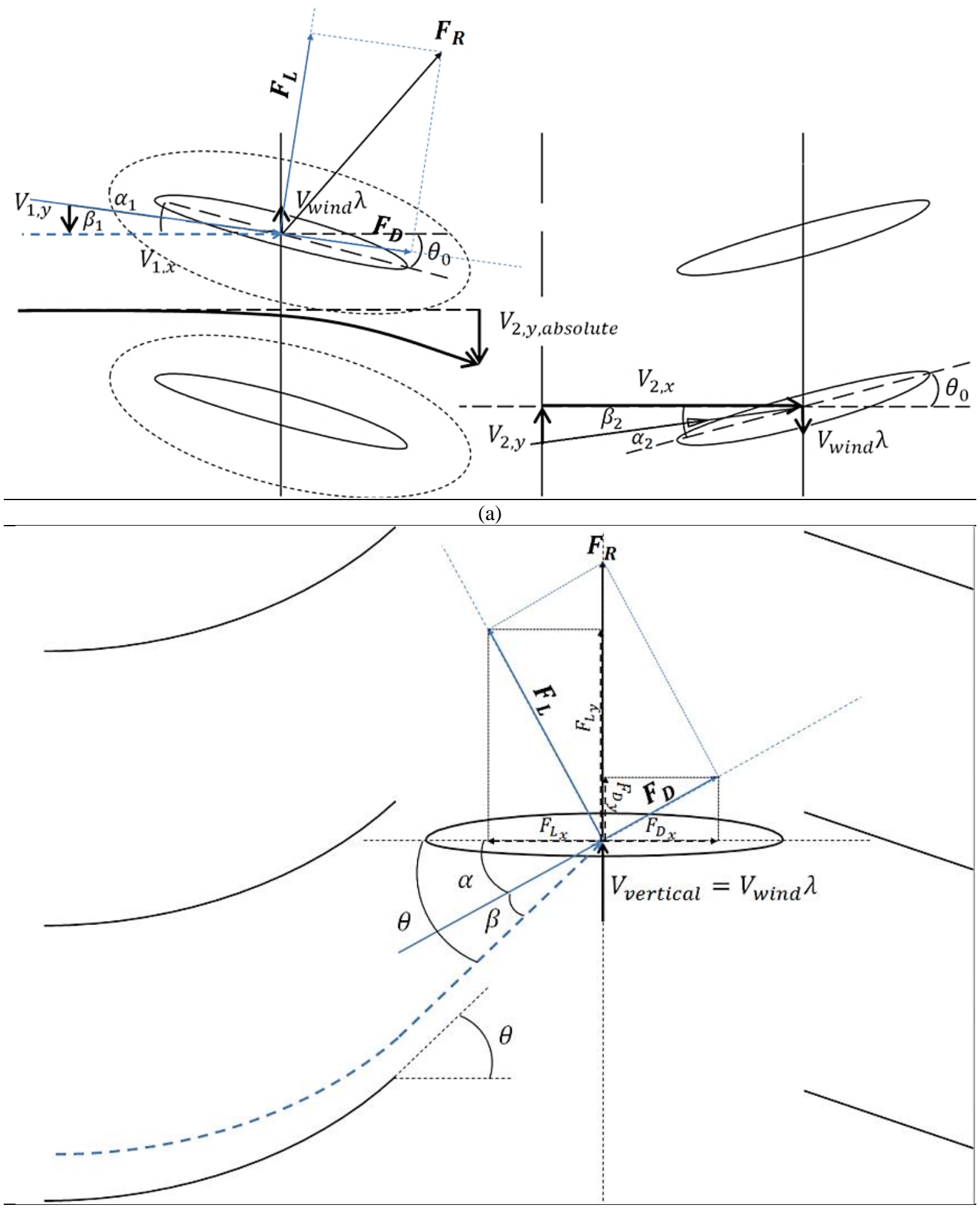

(b)

Figure 5 Aerodynamic forces created on the blades of the: (a) original and (b) stator-augmented PowerWindow. 
Table 1 presents and compares $F_{x}$ and $F_{y}$ on the blades of the original and stator-augmented PowerWindow, and the contribution of the lift $\left(F_{L}\right)$ and drag $\left(F_{D}\right)$ in creating those aerodynamic forces. It can be observed that in the original PowerWindow $F_{L_{x}}$ and $F_{D x}$ strengthen each other and $F_{L_{y}}$ and $F_{D_{y}}$ oppose each other, while in the stator-augmented PowerWindow, $F_{L_{x}}$ and $F_{D_{x}}$ are opposing each other and $F_{L_{y}}$ and $F_{D_{y}}$ are strengthening each other. The opposite act of $F_{L_{x}}$ and $F_{D_{x}}$ in the stator-augmented PowerWindow enables us to control, reduce and even neutralize the undesirable axial load as discussed later.

Table 1 Aerodynamic forces and $\alpha$ created on blades of the original and stator-augmented PowerWindow.

\begin{tabular}{|c|c|c|}
\hline & Original & Stator-augmented \\
\hline$F_{L_{x}}=$ & $1 / 2 \rho B V_{\text {rel }}{ }^{2} C_{L} \sin \beta$ & $1 / 2 \rho B V_{\text {rel }}{ }^{2} C_{L} \sin \alpha$ \\
\hline$F_{D_{x}}=$ & $1 / 2 \rho B V_{\text {rel }}{ }^{2} C_{D} \cos \beta$ & $1 / 2 \rho B V_{\text {rel }}{ }^{2} C_{D} \cos \alpha$ \\
\hline$F_{L_{y}}=$ & $1 / 2 \rho B V_{\text {rel }}{ }^{2} C_{L} \cos \beta$ & $1 / 2 \rho B V_{\text {rel }}{ }^{2} C_{L} \cos \alpha$ \\
\hline$F_{D_{y}}=$ & $1 / 2 \rho B V_{\text {rel }}{ }^{2} C_{D} \sin \beta$ & $1 / 2 \rho B V_{\text {rel }}{ }^{2} C_{D} \sin \alpha$ \\
\hline$F_{x}=$ & $F_{L_{x}}+F_{D_{x}}$ & $F_{L_{x}}-F_{D_{x}}$ \\
\hline$F_{y}=$ & $F_{L y}-F_{D y}$ & $F_{L y}+F_{D y}$ \\
\hline$\alpha=$ & $\theta_{b}-\beta$ & $\theta_{v}-\beta$ \\
\hline
\end{tabular}

Airfoil plan area is shown by $B$. Wind relative velocity shown by $V_{\text {rel }}$, can be calculated as discussed later. Effective angle $(\beta)$, which is created by the perpendicular speed of the PowerWindow blades to the approach wind, as shown in Figure 4(b), is equal to the difference between $\theta_{v}$ and $\alpha\left(\beta=\theta_{v}-\alpha\right)$, and $\alpha$ is obtained as described below.

Power generation by each of front and rear blades can be calculated by multiplying the vertical force exerted on the blade $\left(F_{y i}\right)$ by their linear speed. The total power of PowerWindow is the sum of the power generated by all the blades. As explained before, $\lambda$ is the ratio of the blade's speed to the approach wind velocity:

$$
\lambda=\frac{V_{\text {blade }}}{V_{\text {wind }}}
$$

Power generation of a stator-augmented PowerWindow can be calculated by multiplying $F_{y}$ by the linear speed of the blades $\left(V_{\text {blade }}=V_{\text {wind }} \lambda\right)$ as below:

$$
P_{\text {total }}=\sum_{1}^{N}\left(\frac{\rho B}{2}\right) V_{\text {rel }}^{2}\left[C_{L} \cos \alpha+C_{D} \sin \alpha\right]\left(V_{\text {wind }} \lambda\right)
$$


where $V_{r e l}$ refers to the wind relative velocity magnitude when approaching the PowerWindow blades and can be calculated using the equations below:

$$
\begin{aligned}
& V_{\text {rel }}^{2}=V_{x}^{2}+V_{y}^{2} \\
& V_{x}=V_{\text {wind }}\left(1-a_{f}\right) \\
& V_{y}=V_{x} \tan \alpha-\lambda V_{\text {wind }}=V_{\text {wind }}\left(\left(1-a_{f}\right) \tan \alpha-\lambda\right)
\end{aligned}
$$

The angle of attack $\alpha$ over the front and rear blades $(i=1,2)$ can be calculated using the equation below:

$$
\begin{aligned}
& \beta=\tan ^{-1}\left(\lambda /\left(1-a_{f}\right)\right) \\
& \alpha_{i}=\theta_{v, i}-\beta
\end{aligned}
$$

When $\theta_{v, i}$ is the leading angle of the stator vanes (angle of the flow from the horizontal axis which the stator vanes have created). The value of $\theta_{v, i}$ should be the same for the front and rear stator vanes $\left(\theta_{v, 1}=\theta_{v, 3}\right)$ but it can be different for the middle one $\left(\theta_{v, 2}\right)$.

According to Equation 15, power generation by the front blades of the stator-augmented PowerWindow can be calculated as follows:

$P_{\text {front }}=$

$$
\begin{aligned}
& N\left(\frac{\rho B}{2}\right) \lambda \mathrm{V}_{\text {wind }}{ }^{3}\left(\left(1-a_{f}\right)^{2}+\left(\left(1-a_{f}\right) \tan \theta_{v, 1}-\lambda\right)^{2}\right)\left[C _ { L _ { \alpha 1 } } \operatorname { c o s } \left(\theta_{v, 1}-\tan ^{-1}(\lambda /(1-\right.\right. \\
& \left.\left.\left.\left.a_{f}\right)\right)\right)+C_{D_{\alpha 1}} \sin \left(\theta_{v, 1}-\tan ^{-1}\left(\lambda /\left(1-a_{f}\right)\right)\right)\right]
\end{aligned}
$$

As explained in the previous study ${ }^{10}$, the direction of the flow approaching the rear blades is affected by the front blades, and $\beta_{2}$ and $\alpha_{2}$ may not be equal to $\beta_{1}$ and $\alpha_{1}$, even if: $\theta_{v, 1}=\theta_{v, 2}=$ $\theta_{v, 3}$. Using the affected flow ratio $(\varepsilon)$ investigated in another study ${ }^{8}, \beta_{2}$ and $\alpha_{2}$ can be calculated as follow:

$$
\begin{aligned}
& \beta_{2}=\tan ^{-1}\left((1+\varepsilon) \lambda /\left(1-a_{f}\right)\right) \\
& \alpha_{2}=\theta_{v, 2}-\tan ^{-1}\left((1+\varepsilon) \lambda /\left(1-a_{f}\right)\right)
\end{aligned}
$$

Using $\beta_{2}$ in equation 25 , power generation by the rear blades of the stator-augmented PowerWindow can be calculated as follows: 
$P_{\text {rear }}=$

$$
\begin{gathered}
N\left(\frac{\rho B}{2}\right) \lambda \mathrm{V}_{\text {wind }}{ }^{3}\left(\left(1-a_{f}\right)^{2}+\left(\left(1-a_{f}\right) \tan \theta_{v, 2}-(1+\varepsilon) \lambda\right)^{2}\right)\left[C _ { L _ { \alpha 2 } } \operatorname { c o s } \left(\theta_{v, 2}-\right.\right. \\
\left.\left.\tan ^{-1}\left((1+\varepsilon) \lambda /\left(1-a_{f}\right)\right)\right)+C_{D_{\alpha 2}} \sin \left(\theta_{v, 2}-\tan ^{-1}\left((1+\varepsilon) \lambda /\left(1-a_{f}\right)\right)\right)\right]
\end{gathered}
$$

\subsection{Blade Element Momentum Analysis of Stator-augmented PowerWindow}

Equating the total power generation (Equation 13) from momentum theory with the total power generation of the front and rear blades (Equations 23 and 26) determines $a_{f}$ and then the power generation of the front and rear blades of the stator-augmented PowerWindow as follows:

$$
\begin{gathered}
\frac{1}{2} \rho A \mathrm{~V}_{\text {wind }}{ }^{3} 4 a_{f}\left(1-a_{f}\right)^{2}= \\
N\left(\frac{\rho B}{2}\right) \lambda \mathrm{V}_{\text {wind }}{ }^{3}\left[( ( 1 - a _ { f } ) ^ { 2 } + ( ( 1 - a _ { f } ) \operatorname { t a n } \theta _ { v , 1 } - \lambda ) ^ { 2 } ) \left[C_{L_{\alpha 1}} \cos \left(\theta_{v, 1}-\tan ^{-1}\left(\frac{\lambda}{\left(1-a_{f}\right)}\right)\right)+\right.\right. \\
\left.C_{D_{\alpha 1}} \sin \left(\theta_{v, 1}-\tan ^{-1}\left(\frac{\lambda}{\left(1-a_{f}\right)}\right)\right)\right]+\left(\left(1-a_{f}\right)^{2}+\left(\left(1-a_{f}\right) \tan \theta_{v, 2}-(1+\right.\right. \\
\left.\left.\varepsilon) \lambda)^{2}\right)\left[C_{L_{\alpha 2}} \cos \left(\theta_{v, 2}-\tan ^{-1}\left(\lambda /\left(1-a_{f}\right)\right)\right)+C_{D_{\alpha 2}} \sin \left(\theta_{v, 2}-\tan ^{-1}\left(\lambda /\left(1-a_{f}\right)\right)\right)\right]\right]
\end{gathered}
$$

Table 2 compares $\beta_{i}$ and $\alpha_{i}$ of the original and stator-augmented PowerWindow and power generation by their front and rear blades.

Table 2 Aerodynamic parameters and power generation of the original and stator-augmented PowerWindow

\begin{tabular}{|c|c|c|}
\hline & Original & Stator-augmented \\
\hline$\beta_{1}=$ & $\tan ^{-1}\left(\lambda /\left(1-a_{f}\right)\right)$ & $\tan ^{-1}\left(\lambda /\left(1-a_{f}\right)\right)$ \\
\hline$\alpha_{1}=$ & $\theta_{b}-\beta_{1}$ & $\theta_{v, 1}-\beta_{1}$ \\
\hline$\beta_{2}=$ & $\tan ^{-1}\left(\frac{\left((\varepsilon+1) \lambda-\varepsilon\left(1-a_{f}\right) \tan \theta_{b}\right)}{\left(1-a_{f}\right)}\right)$ & $\tan ^{-1}\left((1+\varepsilon) \lambda /\left(1-a_{f}\right)\right)$ \\
\hline$\alpha_{2}=$ & $\theta_{b}-\beta_{2}$ & \\
\hline
\end{tabular}




\begin{tabular}{|c|c|c|}
\hline$P_{\text {front }}=$ & $\begin{array}{l}N\left(\frac{\rho B}{2}\right) V_{\text {wind }}{ }^{3} \lambda\left(\left(1-a_{f}\right)^{2}\right. \\
\left.+\lambda^{2}\right)\left[\begin{array}{l}C_{L_{\alpha 1}} \cos \left(\tan ^{-1}\left(\frac{\lambda}{\left(1-a_{f}\right)}\right)\right)- \\
C_{D_{\alpha 1}} \sin \left(\tan ^{-1}\left(\frac{\lambda}{\left(1-a_{f}\right)}\right)\right)\end{array}\right.\end{array}$ & $\begin{array}{l}N\left(\frac{\rho B}{2}\right) \lambda V_{\text {wind }}{ }^{3}\left(\left(1-a_{f}\right)^{2}\right. \\
+\left(\left(1-a_{f}\right) \tan \theta_{v, 1}\right. \\
\left.-\lambda)^{2}\right)\left[C_{L_{\alpha 1}} \cos \left(\theta_{v, 1}\right.\right. \\
\left.-\tan ^{-1}\left(\lambda /\left(1-a_{f}\right)\right)\right) \\
+C_{D_{\alpha 1}} \sin \left(\theta_{v, 1}\right. \\
\left.\left.-\tan ^{-1}\left(\lambda /\left(1-a_{f}\right)\right)\right)\right]\end{array}$ \\
\hline$P_{\text {rear }}=$ & $\begin{aligned} & N\left(\frac{\rho B}{2}\right) V_{\text {wind }}{ }^{3} \lambda\left(\begin{array}{c}\left(1-a_{f}\right)^{2}+ \\
\left((\varepsilon+1) \lambda-\varepsilon\left(1-a_{f}\right) \tan \theta_{b}\right)^{2}\end{array}\right. \\
& {\left[C_{L_{\alpha 2}} \cos \left(\tan ^{-1}\left(\frac{\left((\varepsilon+1) \lambda-\varepsilon\left(1-a_{f}\right) \tan \theta_{b}\right)}{\left(1-a_{f}\right)}\right)\right.\right.} \\
- & C_{D_{\alpha 2}} \sin \left(\tan ^{-1}\left(\frac{\left((\varepsilon+1) \lambda-\varepsilon\left(1-a_{f}\right) \tan \theta_{b}\right)}{\left(1-a_{f}\right)}\right)\right.\end{aligned}$ & $\begin{array}{c}N\left(\frac{\rho B}{2}\right) \lambda V_{\text {wind }}{ }^{3}\left(\left(1-a_{f}\right)^{2}+\right. \\
\left(\left(1-a_{f}\right) \tan \theta_{v, 2}-(1+\right. \\
\left.\varepsilon) \lambda)^{2}\right)\left[C_{L_{\alpha 2}} \cos \left(\theta_{v, 2}-\right.\right. \\
\left.\tan ^{-1}\left((1+\varepsilon) \lambda /\left(1-a_{f}\right)\right)\right)+ \\
C_{D_{\alpha 2}} \sin \left(\theta_{v, 2}-\tan ^{-1}((1+\varepsilon) \lambda /\right. \\
\left.\left.\left.\left(1-a_{f}\right)\right)\right)\right]\end{array}$ \\
\hline
\end{tabular}

Adjusting the orientation of the stator vanes can change contribution of the lift $\left(F_{L}\right)$ and drag $\left(F_{D}\right)$ on the resultant force $\left(F_{R}\right)$ over the blades and significantly increase $C_{P}$ and decrease $C_{T}$ of PowerWindow. Using stator vanes may be an effective approach for creating the optimum resultant force on the PowerWindow blades. An ideal $F_{R}$ on the PowerWindow blades has no horizontal component and is purely vertical. In the stator-augmented PowerWindow a zero $C_{T}$ will be achieved when $F_{L_{x}}$ and $F_{D_{x}}$ neutralize each other $\left(F_{x}=F_{D_{x}} \rightarrow F_{R x}=0\right)$ which needs the following condition:

$$
F_{L} \sin \alpha=F_{D} \cos \alpha \rightarrow \frac{\sin \alpha}{\cos \alpha}=\frac{F_{D}}{F_{L}}=\tan \alpha
$$

According to Table $1, \theta_{i}$ which results in $F_{x}=0$ hence $C_{T}=0$ can be calculated as follows:

$$
\begin{aligned}
& \tan \alpha=\frac{C_{D}}{C_{L}} \rightarrow \tan \left(\theta_{v, i}-\tan ^{-1}(\lambda /(1-\mathrm{a}))\right)=\frac{{ }_{D}\left[\theta_{v, i}-\tan ^{-1}(\lambda /(1-\mathrm{a}))\right]}{C_{L}\left[\theta_{v, i}-\tan ^{-1}(\lambda /(1-\mathrm{a}))\right]} \\
& \theta_{v, i}-\tan ^{-1} \frac{C_{D}\left[\theta_{v, i}-\tan ^{-1}(\lambda /(1-\mathrm{a}))\right]}{C_{L}\left[\theta_{v, i}-\tan ^{-1}(\lambda /(1-\mathrm{a}))\right]}=\tan ^{-1}\left(\frac{\lambda}{(1-\mathrm{a})}\right)
\end{aligned}
$$

In the conventional wind turbines and the original PowerWindow model, increasing $C_{P}$ is always associated with increasing $C_{T}$, while in the stator-augmented PowerWindow, $C_{P}$ can be increased while decreasing $C_{T}$, which is highly desirable. Utilising the developed BEM model and 
developing an active control system for adjusting the stator vanes direction, the optimum $\theta_{v, i}$ for the stator vanes can be calculated and adjusted, which based on the approach wind velocity maximizes $C_{P}$ and minimizes $C_{T}$ for the stator-augmented PowerWindow. Moreover, as discussed earlier, another advantage of the stator -augmented model is that the direction of rotation of the turbine remains the same regardless of the direction of the approach wind.

\section{Computational Fluid Dynamic Model}

\subsection{Transition - Turbulence Model}

In CFD simulations, the accuracy of flow separation prediction on every blade is significantly dependent on selecting an appropriate viscous model. The shear stress transport (SST) models have been validated extensively for separating 2D flows with Reynolds-averaged Navier-Stokes (RANS) models ${ }^{23}$. Menter ${ }^{24}$ suggests that flow over the rotor blades can be subject to significant region of laminar-turbulence transition and because the transition process can affect the separation behavior of the boundary layer on the blade surface $v 2-\mathrm{f}$ (transition SST) model is the best model in case of separation. Based on flow over a flat plate ${ }^{25}$, Reynold number of $7.1 \times 10^{4}$ is calculated on the PowerWindow blades in the wind tunnel test, which indicates that blades are located in a laminar-turbulent transition region. Therefore, the $v 2$-f model seems to be the most accurate model for these simulations.

The $v 2$-f model is a modified SST $k$ - $\omega$ RANS turbulence model by the addition of two other

transport equations for $\gamma$ (the intermittency) and the transition onset criteria ${ }^{24}$. Menter ${ }^{24}$ expressed that this approach has two main advantages. The first is that it improves the robustness of the model because the intermittency does not enter directly into the momentum equations. The second advantage is that it allows the model to predict the effects of high free stream turbulence levels on buffeted laminar boundary layers. The reason is that for large free stream eddy viscosities, the small values of intermittency in the boundary layer do not cancel out the local eddy viscosity.

\subsection{Mesh and Boundary Conditions}

In this study, stator vanes at the front and rear of PowerWindow are designed with a curved shape $\left(24^{\circ}\right.$ circle arc) to minimize flow separation from their surface. As a simple preliminary configuration, the stator vanes have been selected to have the same length and distance from each 
other as the chord length of the blades $(150 \mathrm{~mm})$. The $2 m \times 2 m \times 0.8 m$ stator-augmented PowerWindow was located in $6 m \times 8 m \times 14 m$ domain having $3 m$ distance from the inlet and $10 \mathrm{~m}$ from the outlet.

In CFD simulations higher mesh quality is primarily achievable by using finer structured mesh. But, a fully structured mesh usually needs numerous elements which is computationally expensive. In order to achieve a balance between solution accuracy and calculation time, a combination of structured and unstructured mesh is used in this study. This technique helps to decrease the number of elements while having a high quality mesh around the body ${ }^{26}$. Therefore, as previously investigated in the mesh independence study for the CFD model of the PowerWindow prototype ${ }^{27}, 200$ structured rectangular elements (1.5mm length of each cell along the chord-wise direction), with $\mathrm{y}^{+}$below 1.0, are generated adjacent to the blade surface. This structured region, as shown in Figure 6 (c), is connected to the surrounding structured region via unstructured triangular elements with a maximum skewness of 0.17 , as shown in Figure 6(b). The 3D model contains 4,078,320 elements in the original model and 5,128,740 elements in the stator-augmented model. In both cases $\mathrm{y}^{+}$is below 300 over all the walls.

The frame of the hybrid region containing the front and rear blades is selected as multiple reference frame (MRF) which can move vertically within the domain. The boundaries of the blades are set to moving wall with zero velocity relative to their adjacent cells. As a result, their vertical velocity would be equal to the MRF surrounding cells. The inlet boundary condition has a constant free stream velocity of $8 \mathrm{~m} . \mathrm{s}^{-1}$ and the outlet boundary of the domain is set to atmospheric pressure. Turbulence intensity of $5 \%$ and turbulence viscosity ratio (the ratio of turbulent to laminar viscosity) of 10 is set for inlet, and outflow boundary condition was set for outlet. The magnitude of the inlet velocity and turbulent intensity were selected to be consistent with the wind tunnel condition where the first experimental test was undertaken (on the original PowerWindow Prototype). The standard pressure correction method and a first order upwind scheme is used. The top and bottom boundaries of the domain are selected as stationary wall. Gambit ${ }^{28}$ is used as the mesh generation tool in this study. The CFD simulations are at the prototype scale, thus avoiding the need to accommodate any scaling dictated by similarity criteria.

It should be noted that $\lambda$ cannot be determined automatically, it needs to be manually increased. The value of $\lambda$ that results in the maximum power generation gives the ideal operating $\lambda$. 


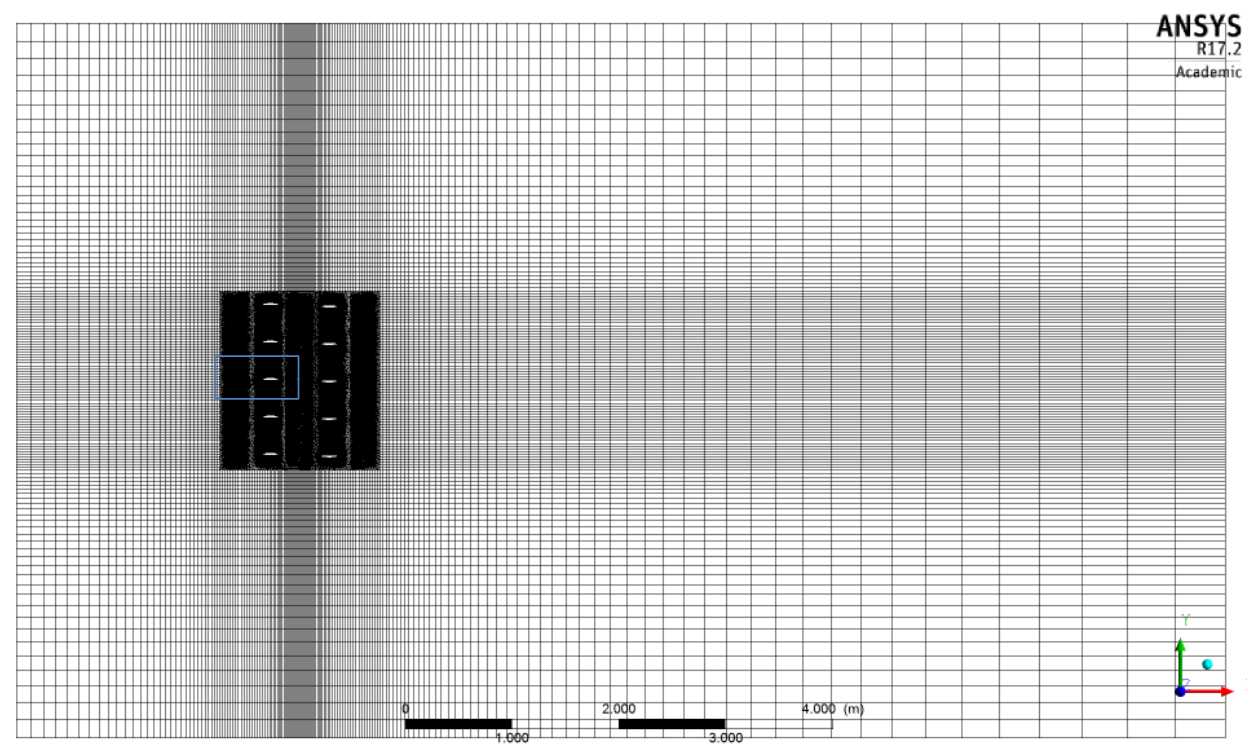

(a)

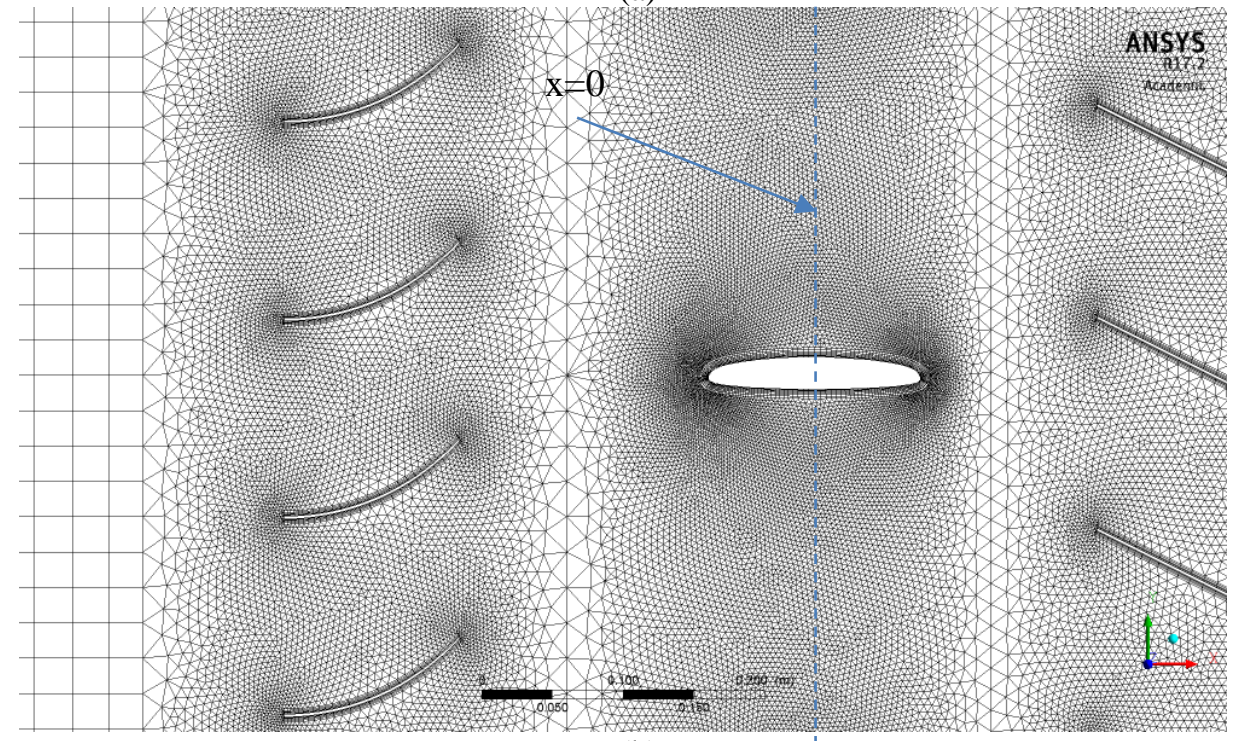

(b)

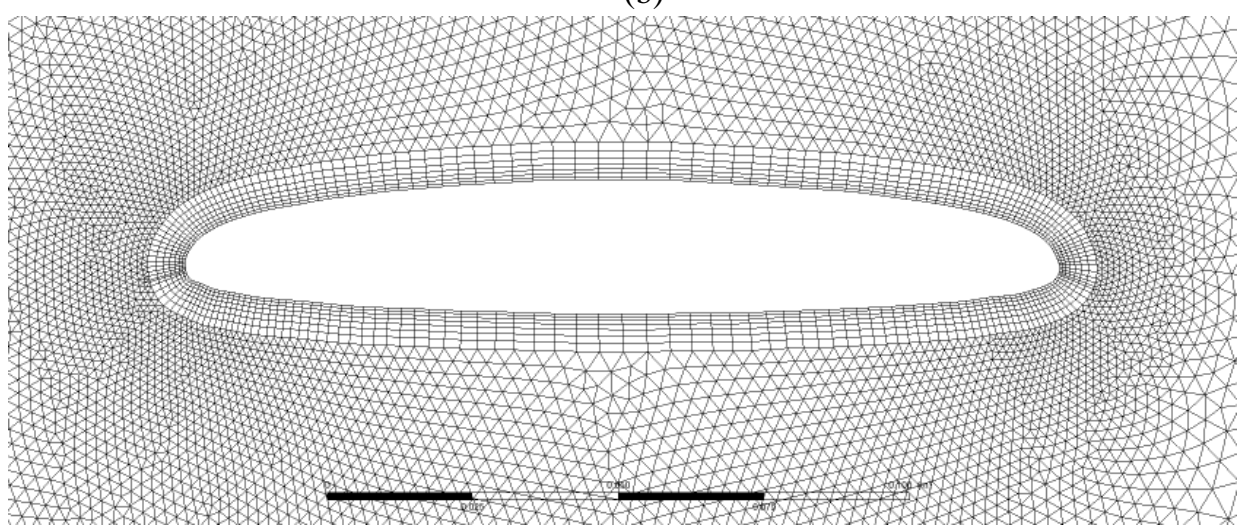

(c)

Figure 6 (a) Structured mesh generated around the unstructured region. (b) Combination of structured and unstructured mesh around the blades (a blue dash line shows $\mathrm{x}=0$ ). (c) Fine structured rectangular elements adjacent to the blade surface. 


\section{Results and Discussion}

\subsection{Power Generation of Stator-augmented PowerWindow Model}

In order to achieve similar power generation by the front and rear blades in the statoraugmented PowerWindow, in the preliminary configuration $\theta_{v, 1}$ and $\theta_{v, 3}$ were selected to have the same value as $\theta_{2}\left(\theta_{v, 1}=\theta_{v, 2}=\theta_{v, 3}=24^{\circ}\right)$. Number of blades are the same as the original PowerWindow which corresponds to the solidity: $\sigma=0.428$. The value of $\varepsilon$ is obtained from another study ${ }^{8}$ and used in the developed BEM model. In order to validate the BEM model of the stator-augmented PowerWindow, the $C_{P}$ achieved by this model has been compared with results obtained by the CFD model with the same approach wind velocity of $8 \mathrm{~m} . \mathrm{s}^{-1}$, and shown in Figure 7. $P_{f}, P_{r}$ and $P_{t}$ indicate the power generation performance of the front blades, rear blades and the total amount.

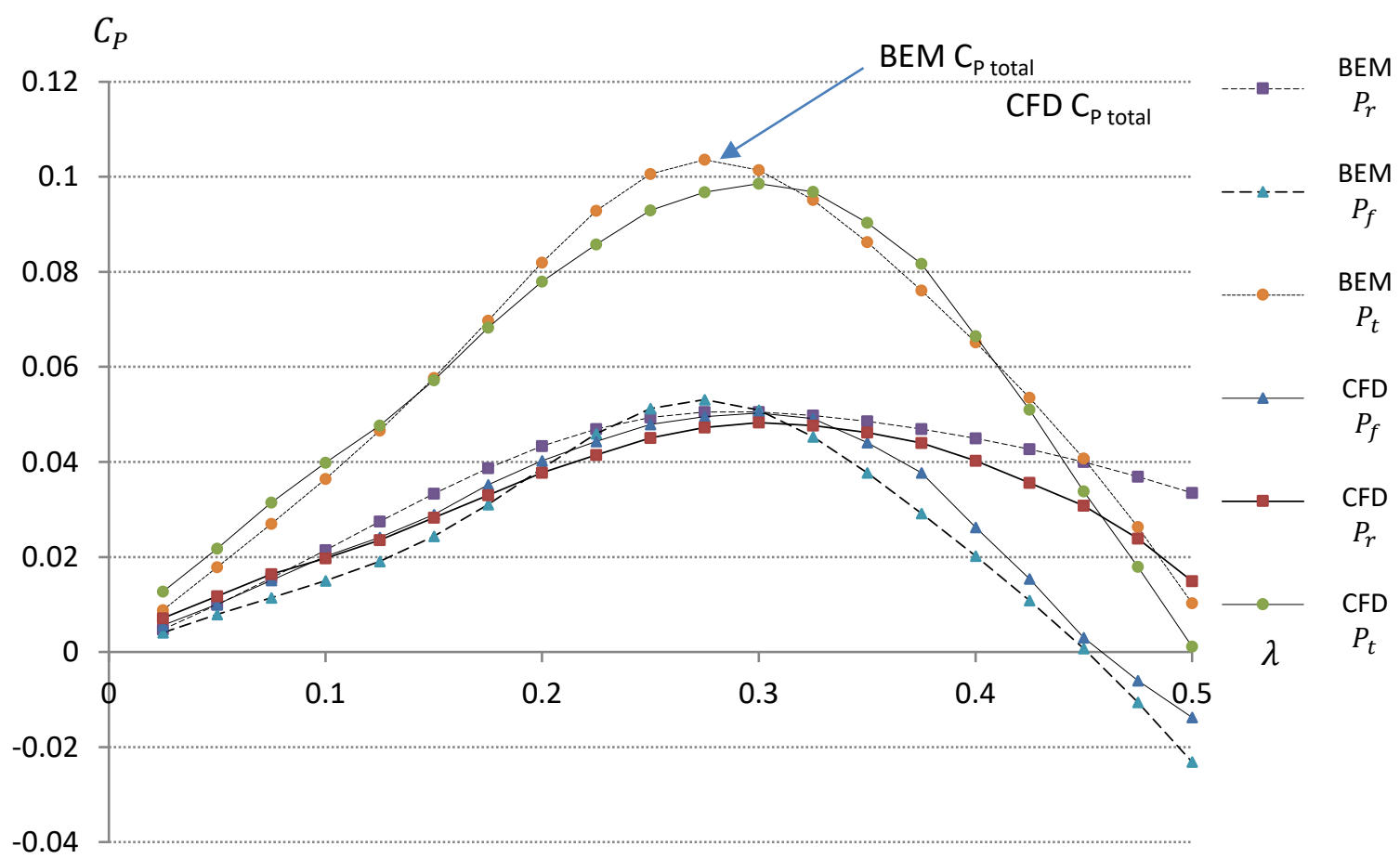

Figure $7 C_{P}$ of stator-segmented PowerWindow when $\sigma=0.428$ versus $\lambda$ when $\theta_{v, 1}=\theta_{v, 2}=\theta_{v, 3}=24^{\circ}$ using modified BEM and CFD models.

Figure 7 shows a reasonable agreement between the results achieved by the CFD model and those calculated by the modified BEM model. Both models have also detected different contributions to the total power generation for the front and rear blades at different $\lambda$, while $\theta_{v, 1}$ and $\theta_{v, 3}$ were selected to have the same value as $\theta_{v, 2}$. The reason is that $\alpha_{1}$ is dependent on $\theta_{v, 1} a_{f}$, 
and $\lambda$ (as shown in Equation 21 and 22) while $\alpha_{2}$ is also dependent on $\varepsilon$ (as shown in Equation 24 and 25). However, an active control system could adjust $\theta_{v, 2}$ so that $\alpha_{1}=\alpha_{2}$. It should be noted that the results obtained by the BEM model are based on a number of simplifying assumptions, including neglecting viscous effects. Furthermore, simplifications such as selecting first order scheme or considering uniform velocity profile at the inlet are generally reflected in the accuracy of the computed results obtained by the CFD model. Although the current results may have some inaccuracies in predicting the aerodynamic performance of the stator-augmented LCWT, they are considered sufficiently reliable to highlight the overall effect of stator vanes on the performance of the device.

\subsection{Aerodynamic Forces of Stator-augmented PowerWindow Model}

Attaching the stator vanes to the PowerWindow blades increases friction and decreases the average velocity within the device, which is undesirable. Meanwhile the stator vanes by changing the flow direction increase the vertical component of velocity toward the blades, which is desirable for power generation. This change demands a higher overall pressure gradient across the statoraugmented model compared with the original PowerWindow. Figure 8 (a) and (b) have plotted velocity and pressure contours in terms of velocity ratio $\left(R_{V}\right)$ and surface pressure coefficient $\left(C_{S P}\right)$ in and around the stator-augmented model. $C_{S P}$ shows the ratio of the local air pressure to the dynamic pressure of the free stream and $R_{V}$ shows the ratio of the local air velocity to the free stream velocity:

$$
\begin{aligned}
& C_{S P}=\frac{P_{\text {static }}}{0.5 \rho V^{2}} \\
& R_{V}=\frac{V_{\text {local }}}{V_{\text {wind }}}
\end{aligned}
$$

Flow streamlines are also mapped over both the $C_{S P}$ and $R_{V}$ contours. As can be seen in Figure 8(a) the front stator vanes have effectively redirected the flow upward, which as expected increase the lift force over the front blades. However, the bottom blade has been located beneath the flow path which means that more stator vanes need to be attached below the front ones to cover the bottom blade. Between the front and rear blades, the middle stator vanes have redirected the flow downward (toward the rear blades). Some flow detachment can be observed over the top stator vanes which as shown in Figure 8(b) have created a low pressure region there. Such flow detachment is not desirable as it partially blocks the flow path and decreases the uniformity of the 
flow approaching the rear blades. One possible solution to reduce flow detachment from the middle vanes surface is to use symmetric airfoil instead of regular flat vanes. 


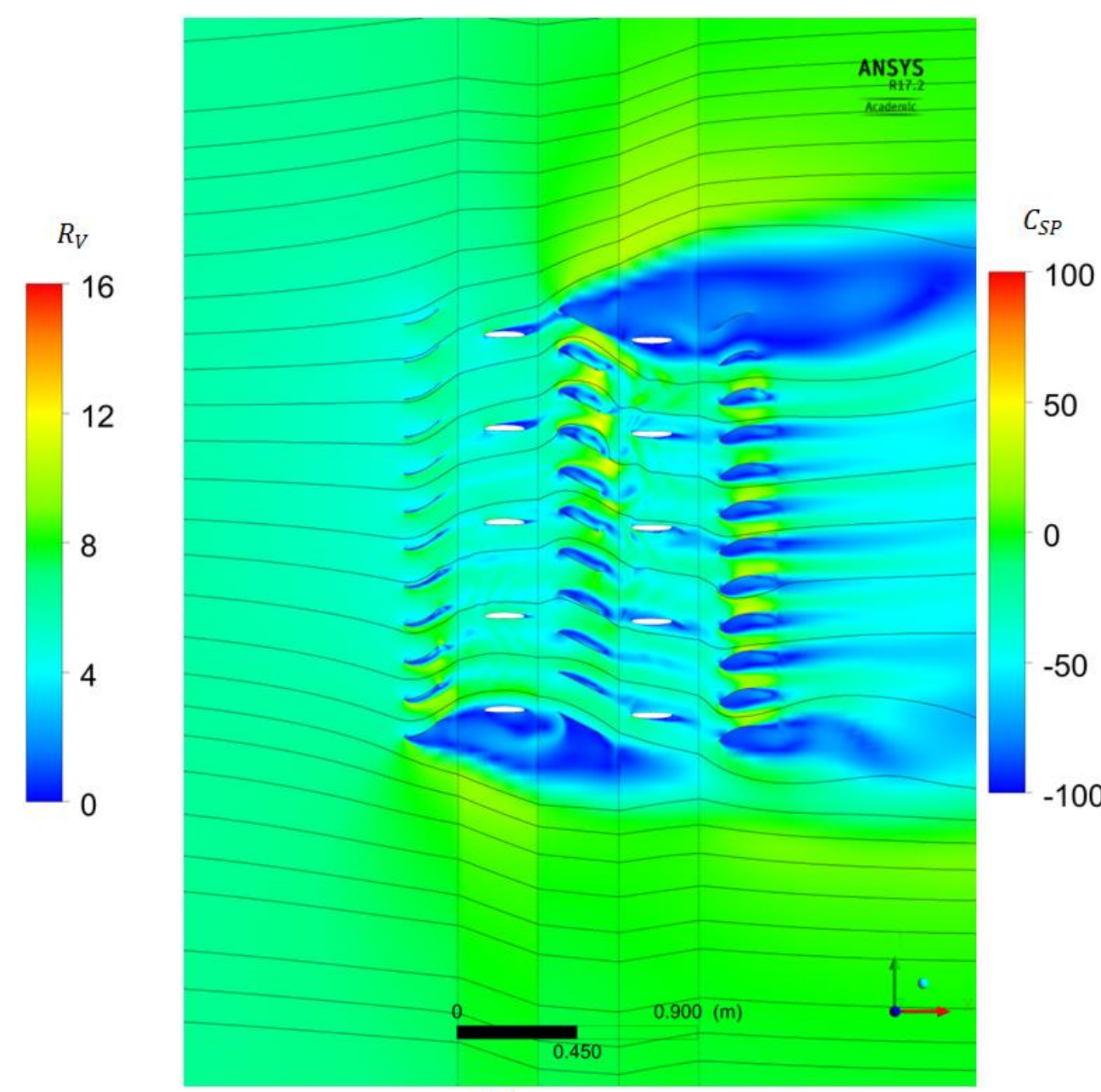

(a)

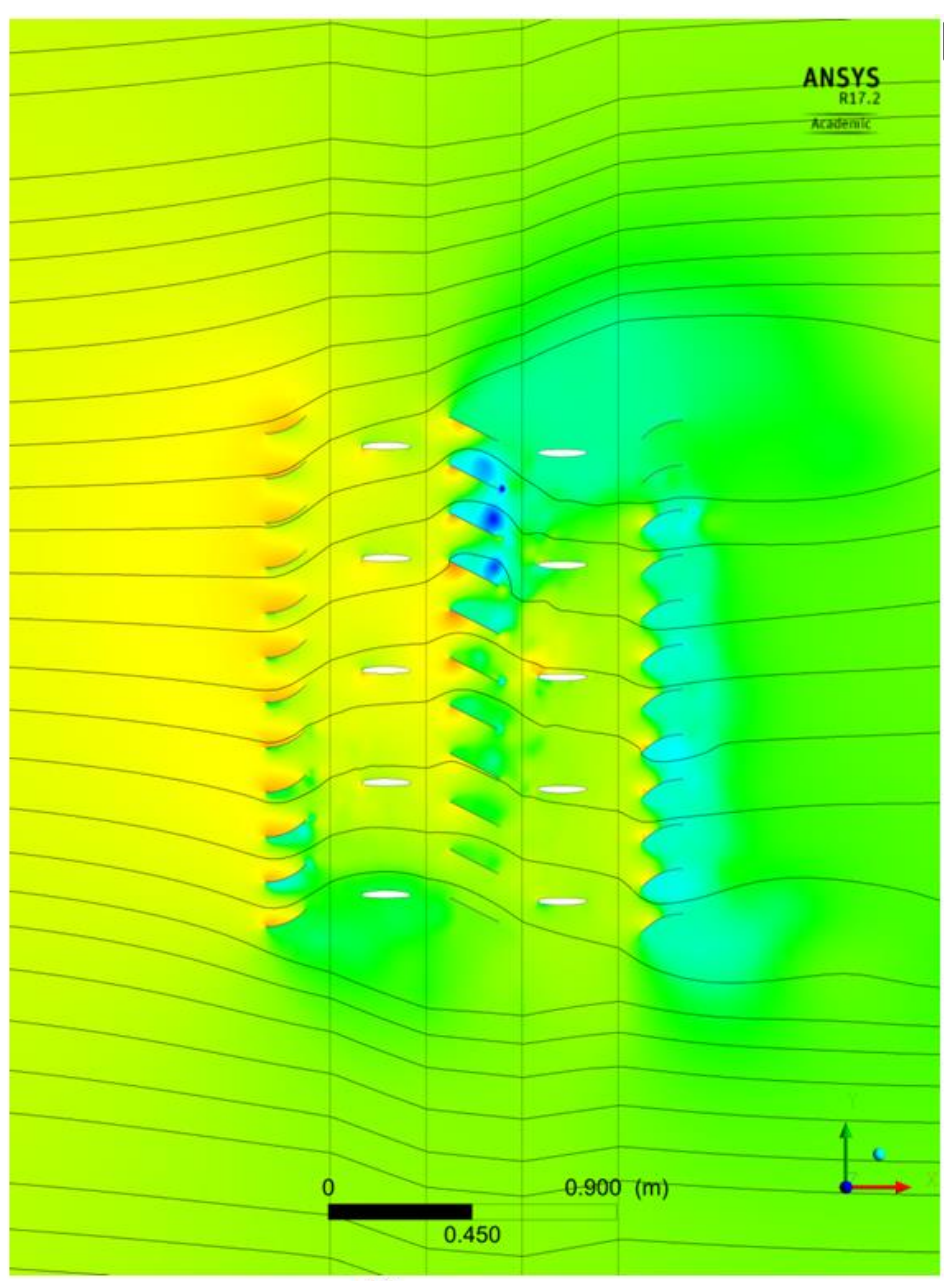

(b)

Figure 8 (a) $R_{V}$ and (b) $C_{S P}$ contours in and around the blades of the stator-augmented PowerWindow. 
Similar to the bottom blade of the front ones, the top blades of the rear ones has been located outside the flow path which means that more stator vanes need to be attached above the middle ones to cover the top blade. As can be observed in both Figures 8(a) and (b), flow detachment is created beneath the rear stator vanes which has created a low pressure region at their downstream. Although it seems that the rear stator vanes have successfully redirected flow to the windward direction, they have resulted in high pressure gradient there. Therefore, in future studies, the length of the front and rear vanes can be altered and/or the curvature of the vanes can be modified to minimize the flow detachment at the outlet.

For investigating the effect of changing flow direction on the aerodynamic forces over the PowerWindow blades, the vertical and axial (windward) aerodynamic forces over the blades of the stator-augmented configuration have been compared with the prototype configuration using CFD simulations.

Figure 9 shows $C_{T}$ of the original and stator-augmented PowerWindow versus $\lambda . T_{f}$ and $T_{r}$ indicate the axial (windward) force over the front and rear blades. Comparison of $F_{x}$ between the original and stator-augmented PowerWindow presented in Table 1 shows that the $F_{x}$ of the stator-augmented PowerWindow is lower than the original one, and $F_{x}$ would be negative $\left(F_{x}<0\right)$ if $F_{D} \cos \alpha$ be greater than $F_{L} \sin \alpha\left(F_{L} \sin \alpha<F_{D} \cos \alpha\right)$ which results in a negative $C_{T}$.

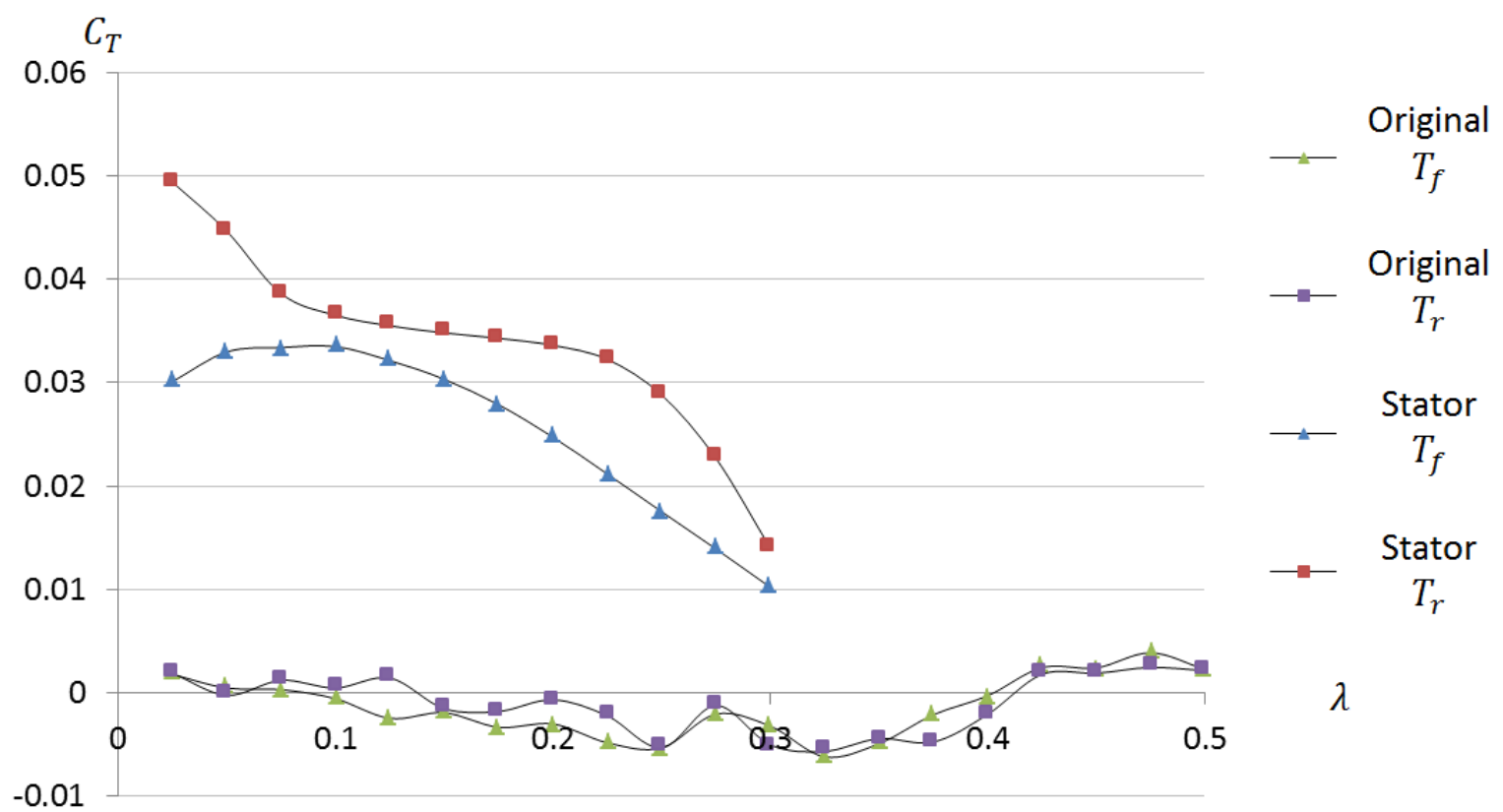

Figure $9 C_{T}$ on the original and stator-augmented PowerWindow versus $\lambda$. 
As shown later in the next figure (Figure 10), the operating point is around $0.15-0.175$ for the original PowerWindow and $0.275-0.325$ for the stator-augmented one. As a result, $C_{T}$ would be around 0.035 for the original PowerWindow and -0.005 for the stator-augmented one. Figure 9 shows that even at other $\lambda \mathrm{s}, C_{T}$ is very low $\left(-0.005<C_{T}<0.005\right)$ in the stator-augmented PowerWindow. The revealed result shows that the stator vanes are able to minimize/neutralize $C_{T}$ on PowerWindow. However, $C_{T}$ has not been completely neutralized by the proposed design and further improvements on the vanes are needed to make that possible.

Figure 10 compares $C_{P}$ of the stator-augmented PowerWindow with contribution of the front and rear blades in the total $C_{P}$ with the original PowerWindow from another study ${ }^{10} . P_{f}, P_{r}$ and $P_{t}$ indicate the power generation by the front blades, rear blades and the total power generation. As comparison between the experimental test on the prototype and its CFD model has shown ${ }^{\text {, }}$ operating $\lambda$ is expected to be around the optimum $\lambda$ in PowerWindow, where the maximum $C_{P}$ is achieved. As can be seen using the stator vanes, PowerWindow can achieve higher $C_{P}$ (around 10\%) at much lower $C_{T}$. This result is very valuable because the main obstacle against enhancing $C_{P}$ of the original model of PowerWindow with increasing $\alpha$ is the destructive axial force which would be inevitably created by increasing $\theta_{b}$.

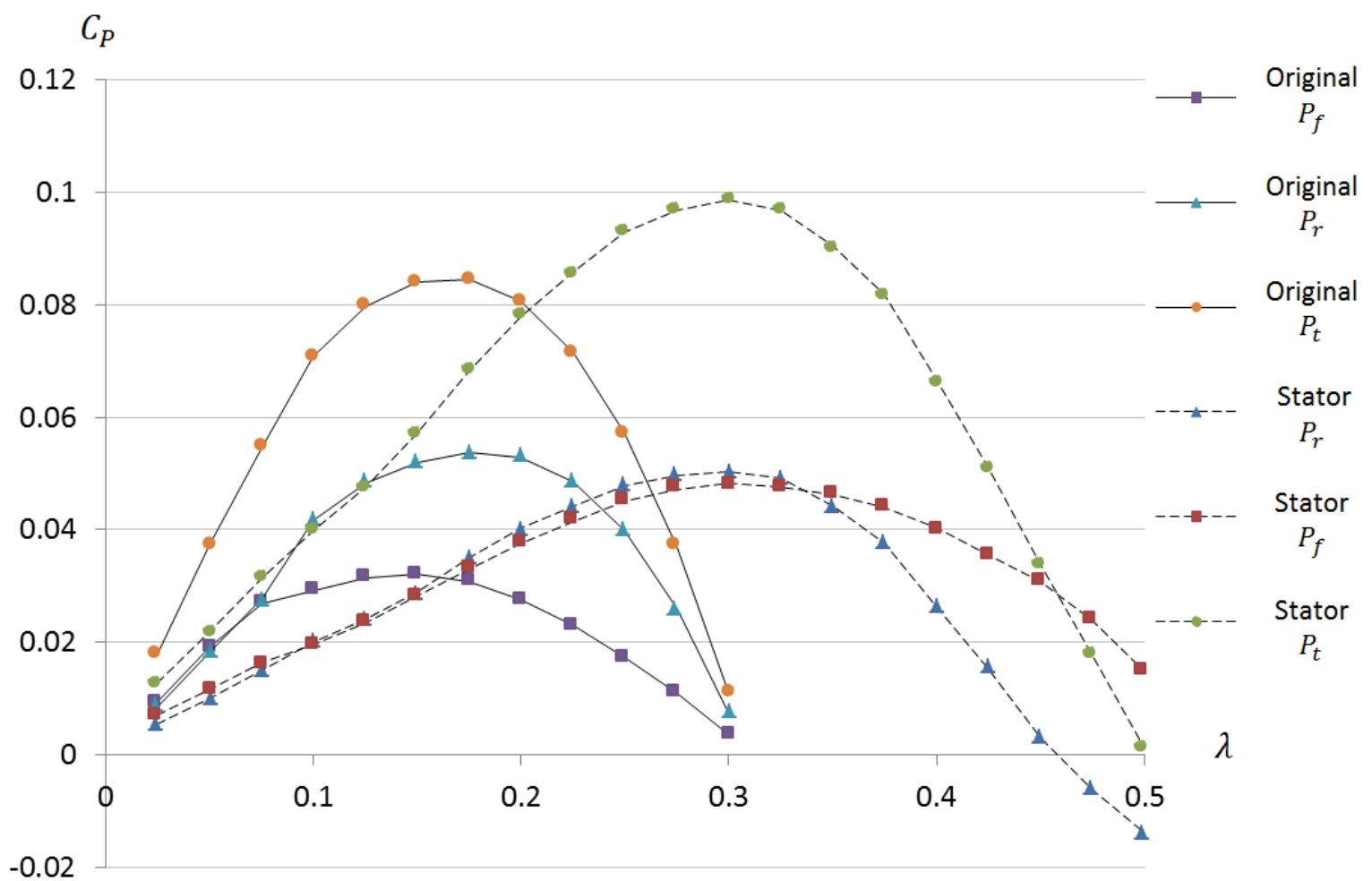

Figure $10 C_{P}$ of the original and stator-augmented PowerWindow versus $\lambda$. 
As shown in the previous study ${ }^{9}$, the relative position of the front blades to the rear ones can

slightly change the aerodynamic forces on the LCWT blades. A similar interaction is expected between the vanes and the blades in the stator-augmented LCWT. The effect of the configuration of stator vanes and the relative position of the vanes to the blades will be investigated in future studies.

\section{Conclusion}

This study has proposed to attach stator vanes to PowerWindow, a linear cascade wind turbine, to improve the flow direction in the device. The stator vanes by controlling the angle of attack increase the acting force (vertical load) and decrease the undesirable force (axial load) on PowerWindow blades. An Analytical model using blade element momentum theory has been developed for the new configuration referred to as stator-augmented PowerWindow. The analytical model has been verified by a computational fluid dynamic model. The results have shown that the stator vanes are able to minimize/neutralize the undesirable force (axial load) on PowerWindow so that the thrust coefficient decreases from 0.035 in the original model to -0.005 in the statoraugmented one. It is shown that the stator vanes by increasing the acting force (vertical load) on PowerWindow blades have simultaneously enhanced the coefficient of performance from 0.85 to 0.1. It is also shown that another advantage of using stator vanes to control the angle of attack is that the direction of rotation of PowerWindow will remain the same regardless of the wind direction. In the original PowerWindow, when the wind direction is reversed, the turbine will also rotate in the opposite direction. The stator-augmented design, therefore, will be particularly useful for fixed in-building installations. 


\section{References}

1. Ponta FL, Lago LI. Analysing the suspension system of variable-geometry oval-trajectory (VGOT) Darrieus wind turbines. Energy for Sustainable Development. 2008;12(2):5-16.

2. Ponta FL, Seminara JJ, Otero AD. On the aerodynamics of variable-geometry oval-trajectory Darrieus wind turbines. Renewable Energy. 2007;32(1):35-56.

3. Otero AD, Ponta FL. On the structural behaviour of variable-geometry oval-trajectory Darrieus wind turbines. Renewable Energy. 2009;34(3):827-832.

4. Islam M, Ting DSK, Fartaj A. Aerodynamic models for Darrieus-type straight-bladed vertical axis wind turbines. Renewable and Sustainable Energy Reviews. 2008;12(4):1087-1109.

5. Mohamed MH. Performance investigation of H-rotor Darrieus turbine with new airfoil shapes. Energy. 2012;47(1):522-530.

6. Mohamed MH. Impacts of solidity and hybrid system in small wind turbines performance. Energy. 2013;57(0):495-504.

7. Lee S, Kim H, Son E, Lee S. Effects of design parameters on aerodynamic performance of a counter-rotating wind turbine. Renewable Energy. 2012;42(0):140-144.

8. Jafari SAH, Kwok KCS, Safaei F, Kosasih B, Zhao M. The effects of installation configuration and solidity on the power generation of a linear cascade wind turbine. Journal of Wind Engineering and Industrial Aerodynamics. 2018;180:122-135.

9. Jafari SAH, Safaei F, Kosasih B, Kwok KCS. Power generation analysis of PowerWindow, a linear wind generator, using computational fluid dynamic simulations. Journal of Wind Engineering and Industrial Aerodynamics. 2015;147:226-238.

10. Jafari SAH, Kwok KCS, Safaei F, Kosasih B, Zhao M. Aerodynamic Analysis of a Linear Cascade Wind Turbine using Blade Element Momentum Theory. Wind Energy

11. Perry RH, Green DW. Perry's Chemical Engineers' Handbook. McGraw Hill; 2007.

12. DiPietro AL. Integrated fan-core twin spool counter-rotating turbofan gas turbine engine. In: Google Patents; 2002.

13. Hwang B, Lee S, Lee S. Optimization of a counter-rotating wind turbine using the blade element and momentum theory. Journal of Renewable and Sustainable Energy. 2013;5(5).

14. Lawn CJ. Optimization of the power output from ducted turbines. Proceedings of the Institution of Mechanical Engineers, Part A: Journal of Power and Energy. 2003;217(1):107-117.

15. Bohorquez F, Pines D, Samuel PD. Small Rotor Design Optimization Using Blade Element Momentum Theory and Hover Tests. Journal of Aircraft. 2010;47(1):268-283.

16. Bedon G, Raciti Castelli M, Benini E. Optimization of a Darrieus vertical-axis wind turbine using blade element - momentum theory and evolutionary algorithm. Renewable Energy. 2013;59(0):184-192.

17. Glauert H. Airplane propellers, Aerodynamic theory, Julius Springer (Berlin. Germany). 1935:169-360.

18. Rajagopalan RG, Mathur SR. Three dimensional analysis of a rotor in forward flight. Journal of the American Helicopter Society. 1993;38(3):14-25.

19. Sørensen JN, Kock CW. A model for unsteady rotor aerodynamics. Journal of Wind Engineering and Industrial Aerodynamics. 1995;58(3):259-275. 
20. Hu Y, Rao SS. Robust Design of Horizontal Axis Wind Turbines Using Taguchi Method. Journal of Mechanical Design. 2011;133(11):111009-111009.

21. Ohyama K, Nakashima T. Wind turbine emulator using wind turbine model based on blade element momentum theory. Paper presented at: Power Electronics Electrical Drives Automation and Motion (SPEEDAM), 2010 International Symposium on; 14-16 June 2010, 2010.

22. Ingram G. Wind Turbine Blade Analysis using the Blade Element Momentum Method. 2005.

23. Shives M, Crawford C. Developing an empirical model for ducted tidal turbine performance using numerical simulation results. Proceedings of the Institution of Mechanical Engineers, Part A: Journal of Power and Energy. 2011.

24. Menter FR. Review of the shear-stress transport turbulence model experience from an industrial perspective. Int J Comput Fluid Dyn. 2009;23(4):305-316.

25. Incropera FP, David P. De Witt. Fundamentals of heat and mass transfer. 1990;4.

26. Jafari SAH, Kosasih B. Flow analysis of shrouded small wind turbine with a simple frustum diffuser with computational fluid dynamics simulations. Journal of Wind Engineering and Industrial Aerodynamics. 2014;125(0):102-110.

27. Jafari SAH, Hassanli S, Kwok KCS. Performance analysis of a small wind turbine mounted inside a tall building. 18th Australasian Wind Engineering Society Workshop; 2016; Serafino Convention Centre, McLaren Vale, South Australia, Australia.

28. Gambit. U.S. Army Research Laboratory DoD Supercomputing Resource Center. http://www.arl.hpc.mil/software/description.html?sw=Gambit. Published 2015. Accessed 2015. 